\title{
Transcription analysis of peloric mutants of Phalaenopsis orchids derived from tissue culture
}

\author{
Ya Huei $\mathrm{CHEN}^{1}$, Yi Jung TSAI ${ }^{2}$, Jian Zhi HUANG ${ }^{3}$, Fure Chyi CHEN ${ }^{1,2,3, *}$ \\ ${ }^{I}$ Institute of Tropical Agriculture \& International Cooperation, National Pingtung University of Science \& Technology, \\ Pingtung 91201, Taiwan \\ ${ }_{2}^{2}$ Institute and Department of Plant Industry, National Pingtung University of Science \& Technology, Pingtung 91201, \\ Taiwan \\ ${ }^{3}$ Institute of Biotechnology, National Pingtung University of Science \& Technology, Pingtung 91201, Taiwan
}

\begin{abstract}
Tissue culture has been widely used for mass propagation of Phalaenopsis. However, somaclonal variation occurred during micropropagation process posed a severe problem by affecting product quality. In this study, wild type and peloric flower buds of Phalaenopsis hybrids derived from flower stalk nodal culture were used for cDNA-RAPD and cDNA suppression subtractive hybridization analyses in order to study their genetic difference in terms of expressed sequence tags. A total of 209 ESTs from normal flower buds and 230 from mutants were sequenced. These ESTs sequences can be grouped into several functional categories involved in different cellular processes including metabolism, signal transduction, transcription, cell growth and division, protein synthesis, and protein localization, and into a subcategory of proteins with unknown function. Cymbidium mosaic virus transcript was surprisingly found expressed frequently in the peloric mutant of $P$. Little Mary. Real-time RT-PCR analysis on selected ESTs showed that in mutant flower buds, a $b Z I P$ transcription factor (TGA1a-like protein) was down-regulated, while up-regulated genes include auxin-regulated protein kinase, cyclophilin, and $T C P$-like genes. A retroelement clone was also preferentially expressed in the peloric mutant flowers. On the other hand, ESTs involved in DNA methylation, chromatin remodeling and posttranscriptional regulation, such as DNA methyltransferase, histone acetyltransferase, ERECTA, and DEAD/DEAH RNA helicase, were enriched in normal flower buds than the mutants. The enriched transcripts in the wild type indicate the down regulation of these transcripts in the mutants, and vice versa. The potential roles of the analyzed transcripts in the development of Phalaenopsis flowers are discussed.
\end{abstract}

Keywords: Phalaenopsis, tissue culture, peloric mutant, cDNA-RAPD, suppression subtractive hybridization.

\section{INTRODUCTION}

Orchid production has become a world-wide business important in floricultural industry [1]. In subtropical and temperate areas, phalaenopsis becomes the most important for orchid production, due to its showy, long-lasting flowers and a large selection of flower colors.

\footnotetext{
*Correspondence: Fure Chyi CHEN

Department of Plant Industry, National Pingtung University of Science \& Technology, Pingtung 91201, Taiwan

E-amil: fchen@mail.npust.edu.tw

Abbreviations: EST (Expressed sequence tag); cDNA-RAPD (Randomly amplified polymorphic cDNAs); SSH (Suppression subtractive hybridization).
}

New clones of orchid hybrids are selected annually by different breeding programs and mass propagated through tissue culture using either meristem or inflorescence tip and nodes as starting materials [2-5]. In commercial laboratories, two methods are used to massively produce an elite orchid clone. Shoot multiplication from pre-existed nodal buds or meristems was adopted by many companies. The drawback of the method is the low speed of proliferation of multiple shoots for mass production. To overcome this, others used an alternative approach by inducing protocorm-like bodies (PLBs) from shoot tips or leaves and then further propagating for secondary or tertiary PLBs to obtain a large quantity $[2,3,6-8]$. The PLBs will then differentiate into plantlets in later stage of micropropagation. 
However there are unpredictable mutations or somaclonal variation occurred during the process of multiplication. Some hybrids are more amenable than others to somaclonal variation. The percentage of the variations ranges from 0 $100 \%$ depending on varieties, with an average of $10 \%$ among phalaenopsis hybrids [9]. Ploidy level change was not detected among tested hybrids from tissue culture when analyzed by flow cytometry [9]. However, 2,4-D was reported to affect ploidy levels in suspension cultures of Doritaenopsis [10]. Peloric flower as well as flower color mutants occurred in many orchid hybrids through tissue culture process $[11,12]$.

The cause of somaclonal variation in higher plants has been reported during different biochemical and molecular events, including changes in DNA methylation pattern, activation of transposable elements or retroelements, and chromosome remodeling [13-19]. Rice retrotransposons could be activated during the process of tissue culture [14]. Activation of some retrotransposons has been found linked to chemical and physical causes, and biotic stresses, such as wounding and pathogen infection $[17,20]$. Molecular markers have been exploited for the detection of somaclonal variation, including RAPD [21, 22], Methylation sensitive RFLP [18, 23, 24], and microsatellite sequence variation [25]. In tissue culture derived plantlets of oil palms, reduced level of DNA methylation in general has been observed [18]. Somaclonal variation has also been reported in phalaenopsis by RAPD analysis on regenerated plants, which showed morphological and physiological changes in the flowers [21]. The microsatellite instability could be induced by mutation in mismatch repair genes and by pathogen infection in the inflorescence [2527].

Epigenetic changes in orchids have not been studied in depth so far. Due to limited information of classical genetic map and genomic sequences for phalaenopsis orchid, conventional molecular biological approach becomes the major tool for analysis of orchid development and developmental regulation. The variable genome sizes of
Phalaenopsis among different species [28-30] make the genetic analysis more complicated. Mutants obtained from different methods, such as chemical mutagenesis, T-DNA insertion, and in vitro culture, provide opportunities to pursue developmental process of orchids. In this report, we described transcript profiling of a phalaenopsis peloric flower mutant derived from tissue culture, using randomly amplified polymorphic cDNAs (cDNA-RAPD) and suppression subtractive hybridization (SSH) methods. Expression levels of selected cDNA clones were then compared to the wild type as well as peloric and semi-peloric mutants using real-time RT-PCR to achieve informative understanding of peloric mutants from transcripts level.

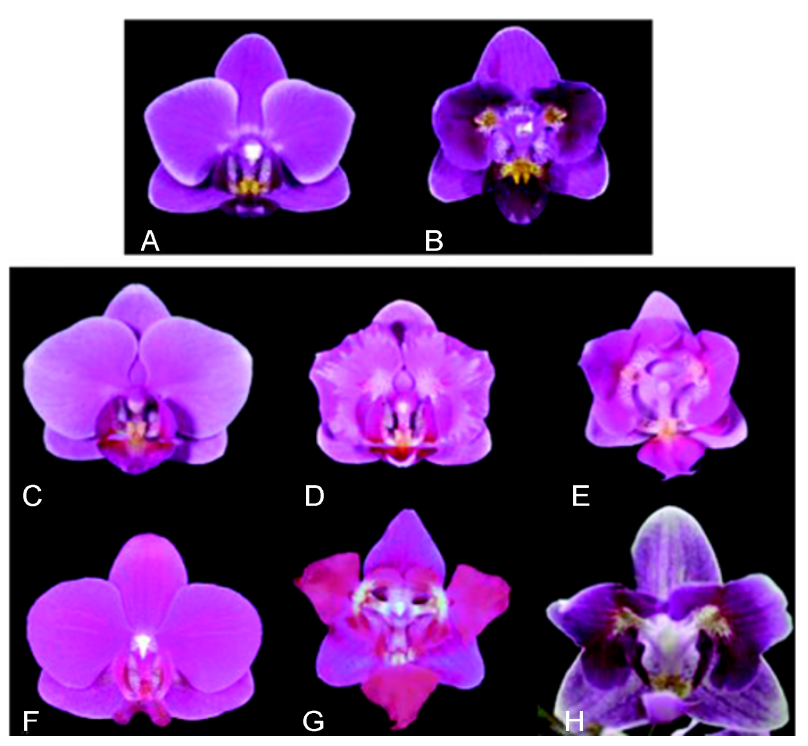

Fig. 1 Morphology of Phalaenopsis flowers used in the experiments. (A) Wildtype flower of $P$. Zuma's Pixie ' $\# 1$ ', (B) Semi-peloric flower of $P$. Zuma's Pixie ' $\# 1$ '. (C) Wildtype flower of $P$. Little Mary, (D) Semi-peloric flower of $P$. Little Mary, (E) Peloric flower of $P$. Little Mary. (F) Wildtype flower of Doritaenopsis Minho Diamond 'F607'. (G) Peloric flower of Dtps. Minho Diamond 'F607', (H) Peloric flower of $P$. hybrid D.

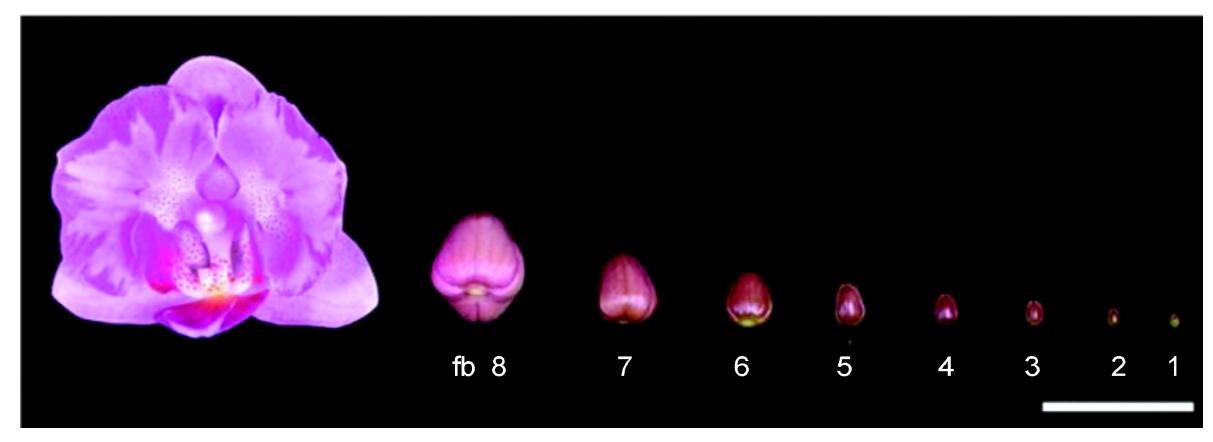

Fig. 2 Developmental stages of flower buds of $\boldsymbol{P}$. Little Mary. $(\mathrm{fb} 1-\mathrm{fb} 8)(\mathrm{bar}=2 \mathrm{~cm})$ 


\section{MATERIALS AND METHODS}

\section{Plant materials and RNA isolation}

For cDNA-RAPD analysis, four different sets of Phalaenopsis plants were used, including wildtype and semi-peloric flowers and flower buds of $P$. Zuma's Pixie (Obtained from Taida Orchids, Changhwa, Taiwan), P. Little Mary 'F535' and Doritaenopsis Minho Diamond 'F607' (obtained from Sogo Orchids, Pingtung, Taiwan). For cDNA subtraction, $P$. Little Mary 'F535' and an unknown hybrid (designated as $P$. D) were used (Fig. 1). For all experiments, flower buds younger than stage 4 (Fig. 2) were harvested and frozen in the liquid nitrogen then stored at $-80^{\circ} \mathrm{C}$ until use.

Total RNAs were isolated and purified using the TRIZOL reagents according to the manufacturer's instructions (Invitrogen). RNA precipitates were resuspended in DEPC-treated sterile water and precipitated with $\mathrm{LiCl}$ (a final concentration of $2 \mathrm{M}$ ). The supernatant was treated with RNase-free DNase (Promega) at $37^{\circ} \mathrm{C}$ for 30 min to remove residual genomic DNAs. Purified RNAs were quantified using a spectrophotometer (Hitachi U2000) and quality checked by agarose electrophoresis.

\section{cDNA synthesis, RAPD, and cloning of DNA}

Double stranded cDNAs were synthesized from $1 \mu \mathrm{g}$ total RNAs using the SMART PCR cDNA Synthesis Kit following the manufacturer's instructions (Clontech). For RAPD analysis, the random decamer primers were obtained from Operon. The reaction mixtures contain $200 \mu \mathrm{g}$ cDNA, $1 \times$ PCR buffer, dNTPs, $2 \mu \mathrm{M}$ random primer, and $1 \mathrm{U}$ of Taq DNA polymerase (Takara) in a total volume of $20 \mu$ l. The PCR condition was as follow: $94^{\circ} \mathrm{C}$ for $5 \mathrm{~min}$, then 35 cycles of $94^{\circ} \mathrm{C} 30 \mathrm{~s}, 38^{\circ} \mathrm{C} 30 \mathrm{~s}, 72^{\circ} \mathrm{C} 1 \mathrm{~min}$, and finally an extension of $7 \mathrm{~min}$ at $72^{\circ} \mathrm{C}$. The amplified DNA products were separated on $2 \%$ agarose gel.

Differentially amplified DNA bands were purified and ligated into pGEM-T Easy vector (Promega). The positive inserts were checked by PCR using universal primers T7 and SP6. The cloned DNA fragments were sequenced with the ABI PRISM 3100 sequencer.

\section{Suppression subtractive hybridization and DNA sequencing}

To compare gene expression in flower buds of the peloric mutants and wild type of $P$. Little Mary, SSH was conducted as described previously [31]. For comparison of differential gene expression in flowers and leaves, the peloric unknown hybrid $P$. D with similar flower color and size was used. Poly $\mathrm{A}^{+} \mathrm{RNAs}$ were isolated from $75 \mu \mathrm{g}$ total RNAs using the Oligo (dT) ${ }_{25}$ containing Dynabeads following manufacturer's instruction (Dynal Biotech). Equal amounts of poly $\mathrm{A}^{+}$RNAs $(2 \mu \mathrm{g})$ from flower buds and leaves were converted into double stranded cDNAs using the SMART PCR cDNA Synthesis Kit (Clontech).

Two subtracted libraries were constructed by using the PCRSelect cDNA Subtraction kit (Clontech). In both libraries, the wild type flower buds of $P$. Little Mary were used as driver and peloric flower buds as tester, and vice versa. A third subtracted library was constructed to compare the transcripts in flower buds and leaves, the $P$. D hybrid leaves were used as driver and peloric flower buds as tester. The subtracted clones were purified and cloned into pGEM$\mathrm{T}$ Easy vector and positive inserts were sequenced.

Tab. 1 Primers used for real-time PCR analysis

\begin{tabular}{llc}
\hline \multicolumn{1}{c}{ Primer name } & \multicolumn{1}{c}{ Sequence $\left(5^{\prime} \rightarrow 3^{\prime}\right)$} & Length (mer) \\
\hline Endogenous control & & 22 \\
ACTIN4-1 & TTGTGAGCAACTGGGATGACAT & 19 \\
ACTIN4-2 & GCCACGCGAAGTTCATTGT & 23 \\
Darget genes & CCGTCTGCAATTTTTTCCTAATG & 20 \\
D20-2 & CCTGCCTTTCCTTTAGC & 25 \\
OPT05M-50-1 & GTTCAAGACAATGACGACGTTTATG & 23 \\
OPT05M-50-2 & GTGGATGAAAAGCAAGGAAAGTG & 21 \\
ZOPAA01M-2(72)-1 & CATGTCGTCACCGGCGTATAC & 25 \\
ZOPAA01M-2(72)-2 & ACAACGCCACCAGATACCATATTAA & 30 \\
ZOPB10M-60-2(1)-1 & TCTCCCTGTTAGAAGTTCAAGAAGTACTAC & 20 \\
ZOPB10M-60-2(1)-2 & GCCATCTCACCACCAAAAGC & 22 \\
ZOPAA12M-24(65)-1 & GTCCCCAAGACTGCAGAAAACT & 20 \\
ZOPAA12M-24(65)-2 & TGCGGCCTATACCCATTTCA & 25 \\
607FD12-1 & GAGAGATCAAGACCAACTAAAACAT & 20 \\
607FD12-2 & GCTGCTTCCCTTTGTCGATT & 21 \\
LOPW12M-4-1(7)-1 & CACGGGTGACCTGCTAAATTC & 21 \\
LOPW12M-4-1(7)-2 & GCTCCTGATCTTTTGCGTTTG & 26 \\
LOPW02N-3-2(3)-1 & ATAGTCAAAGGATGCTCCTCGAGATA & \\
LOPW02N-3-2(3)-2 & GATTTGTTTGCTTCCTGGTCATAA & 24 \\
LOPW06N-11-3(19)-1 & CGCCCGTTGCGAGATCT & 17 \\
LOPW06N-11-3(19)-2 & CATTAGTATTTAGGCCCGATGGAA & 24 \\
LOPW07N-13(29)-1 & GGATTTCTGAAGGTCTCGGACAT & 23 \\
LOPW07N-13(29)-2 & GCCCTGATGGATTTCCTGATT &
\end{tabular}

${ }^{\mathrm{a}}$ Accession no.: AY134752 


\section{Sequence analysis}

The cDNA sequences were compared for similarities against GenBank with the BLASTX [32]. The resulted matches were annotated. Classification of annotated sequences was according to the method described in [33].

\section{Real-Time reverse transcriptase PCR assay}

Real-time RT-PCR and data analysis were performed in the ABI PRISM 7900 Sequence Detection System using $2 \times$ SYBR Green Master Mix to monitor dsDNA synthesis (Applied Biosystems). The gene-specific forward and reverse primers (Tab. 1) were designed based on cloned partial cDNA sequences following the directions of Primer Express 2.0 (Applied Biosystems) and synthesized by Mission Biotechnology (Taipei). Each primer pairs was designed to amplify around $60-80 \mathrm{bp}$ length to allow optimized estimation. For controlling the integrity of RNA and normalizing target RNA copy numbers in mutant and wild type flower buds, the housekeeping gene actin (PACT4, AY134752) was amplified by real-time RTPCR to generate a standard curve of actin mRNA levels. In order to distinguish the expression levels of individual target genes, their standard curves, used as the calibrators, were established using single stranded cDNAs of the wild type flower buds.

PCR condition was essentially as described in Czechowski et al.
[34] except that the total reaction volume was $25 \mu 1$ for each sample and half amount of the $2 \times$ SYBR Green $(12.5 \mu \mathrm{l})$ was added. We found this amount of the dye sufficient for PCR analysis. PCR condition was as follow: $50^{\circ} \mathrm{C}$ for $2 \mathrm{~min}, 95^{\circ} \mathrm{C}$ for $10 \mathrm{~min}$, then 40 cycles of $95^{\circ} \mathrm{C} 15 \mathrm{~s}, 60^{\circ} \mathrm{C} 1 \mathrm{~min}$, after that, one more cycle at $95^{\circ} \mathrm{C} 15 \mathrm{~s}, 60^{\circ} \mathrm{C}$ $15 \mathrm{~s}$ and $95^{\circ} \mathrm{C} 15 \mathrm{~s}$. Standard curve (Ct value against log ng template) for each target and housekeeping gene was established according the guides provided by the ABI PRISM 7900 Sequence Detection System.

\section{RESULTS}

\section{Morphology of peloric mutant flowers}

Wild type Phalaenopsis flowers possess three petal-like sepals, with one in the top or dorsal sepal, and two lower lateral sepals. There are two lateral petals and a specialized enlarged flamboyant bottom petal, called lip or labellum (Fig. 1A, C, F). In the middle of the flower there is a pistil/ stigma fused together with pollinia to form so called column or gynostemium (Fig. 1). In rare cases some seedlings from sexual hybridization may generate lip-like lateral petals. When a selected orchid plant was propagated by flower stalk nodal culture, some clones showed differ-
A

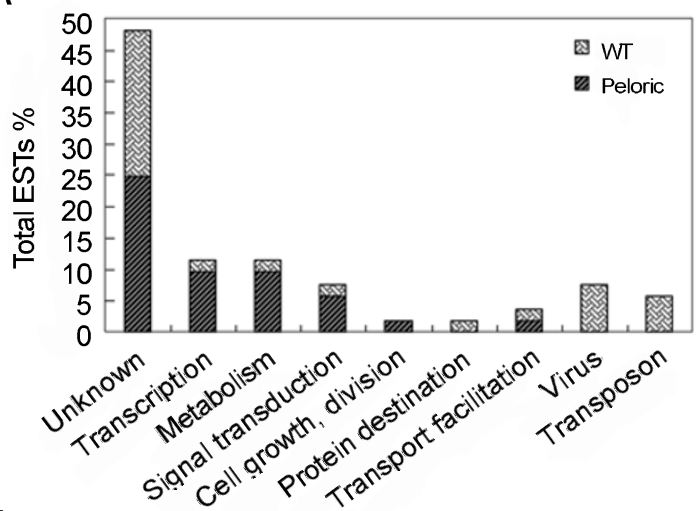

C

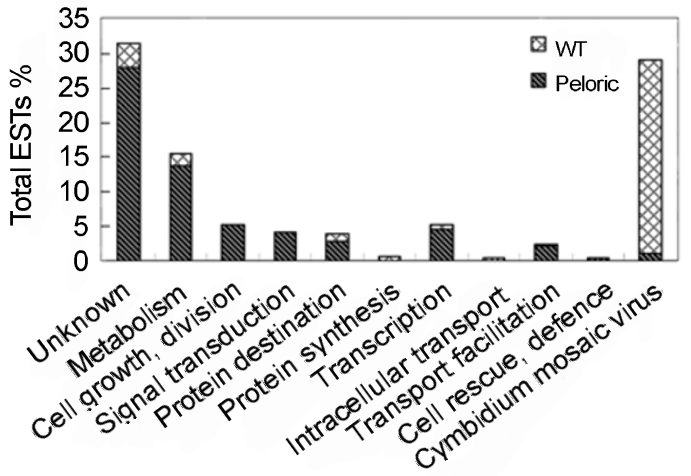

B
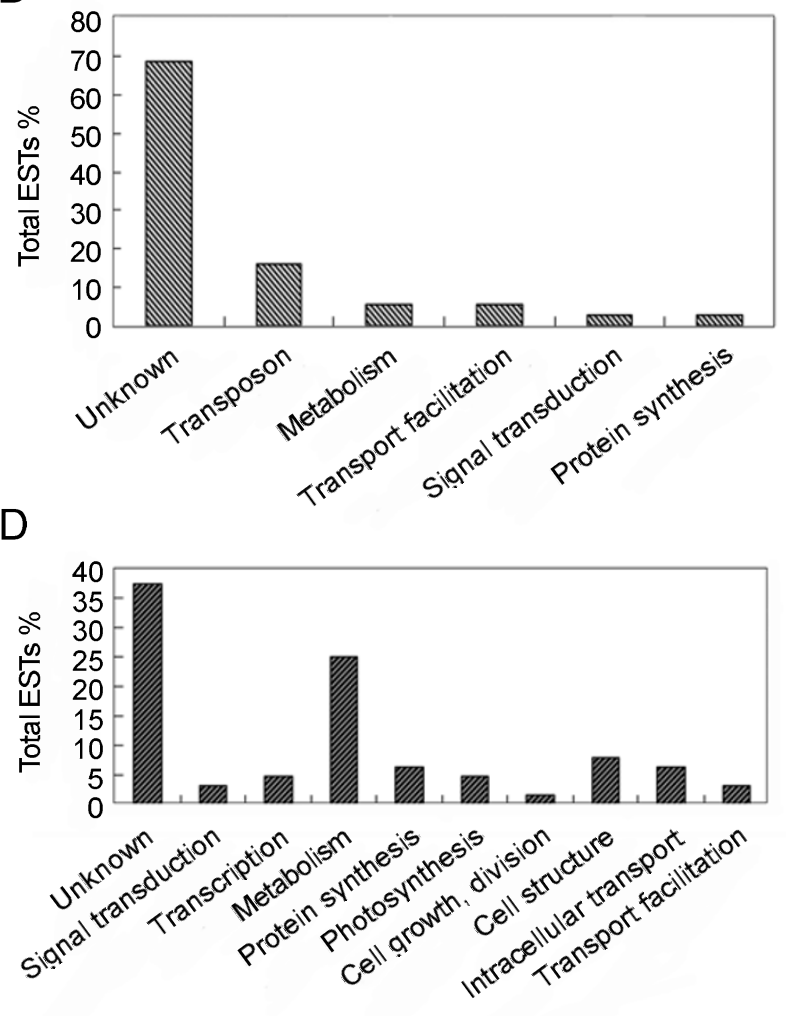

Fig. 3 Functional category of the ESTs in Phalaenopsis flower buds. (A) ESTs from wild type (WT) and peloric mutant flower buds by cDNA-RAPD. (B) ESTs preferentially enriched in flower buds from cDNA-RAPD flower-to-leaf analysis. (C) ESTs enriched in either wild type or peloric mutants of $P$. Little Mary after SSH. (D) ESTs enriched in the peloric flower buds of $P$. Little Mary after flower-leaf SSH. 
Tab. 2 Homology search of ESTs enriched in wildtype flowers by cDNA-RAPD flower-flower assay

\begin{tabular}{|c|c|c|c|}
\hline Clone ID & Description $^{\mathbf{a}}$ & Score (bits) ${ }^{\mathrm{b}}$ & E value $^{\mathrm{c}}$ \\
\hline LAA02N-3-2(3) & RNA polymerase sigma subunit SigE [Arabidopsis thaliana] & 152 & $4.00 \mathrm{E}-36$ \\
\hline LOPW02N-3-2(3) & DNA binding protein TGA1a homolog [Arabidopsis thaliana] & 224 & $1.00 \mathrm{E}-57$ \\
\hline LOPW02N-3-3(5) & putative arabinosyl transferase [Mycobacterium leprae] & 33.1 & 0.72 \\
\hline LOPW06N-11-2(17) & unknown protein $[$ Arabidopsis thaliana $]$ & 80.5 & $2.00 \mathrm{E}-14$ \\
\hline LOPW06N-11-3(19) & protein kinase [Zea mays] & 292 & $2.00 \mathrm{E}-78$ \\
\hline LOPW06N-11-4(21) & putative protein $[$ Arabidopsis thaliana $]$ & 89.7 & $2.00 \mathrm{E}-17$ \\
\hline LOPW07N-13(29) & proline iminopeptidase [Arabidopsis thaliana $]$ & 224 & $1.00 \mathrm{E}-57$ \\
\hline LOPW10N-19(39) & $\begin{array}{l}\text { putative Rhizobium-induced nodule development associated protein } \\
\text { [Oryza sativa] }\end{array}$ & 52 & $1.00 \mathrm{E}-06$ \\
\hline LOPX01N-41(47) & $\mathrm{ABC}$ transporter family protein $[$ Arabidopsis thaliana $]$ & 33.9 & 1.9 \\
\hline LOPX03N-45-2(51) & TCTR2 protein [Lycopersicon esculentum] & 72 & $3.00 \mathrm{E}-12$ \\
\hline LOPX11N-61(57) & putative serine carboxypeptidase I[Arabidopsis thaliana $]$ & 48.1 & $6.00 \mathrm{E}-09$ \\
\hline LOPX13N-65(60) & hypothetical protein [Pyrococcus horikoshii] & 32.7 & 0.89 \\
\hline OPF08N-15(9) & putative SEC1 family transport protein [Arabidopsis thaliana] & 116 & $3.00 \mathrm{E}-25$ \\
\hline OPW04N-7 & putative amidase [Arabidopsis thaliana] & 105 & $2.00 \mathrm{E}-22$ \\
\hline OPW06N-11 & agCP14211 [Anopheles gambiae str. PEST] & 32.3 & 0.002 \\
\hline OPW20N-39 & putative cellulosomal anchoring protein [Ruminococcus flavefaciens] & 32.7 & 3.4 \\
\hline OPX13N-65(2) & unknown protein $[$ Arabidopsis thaliana] & 98.6 & $1.00 \mathrm{E}-20$ \\
\hline OPX13N-66 & anthocyanidin synthase [Torenia fournieri] & 67.4 & $3.00 \mathrm{E}-11$ \\
\hline OPY06N-11 & centromere protein-like [Arabidopsis thaliana] & 73.2 & $6.00 \mathrm{E}-14$ \\
\hline OPY09N-17 & putative pollen specific protein SF21 [Oryza sativa] & 176 & $2.00 \mathrm{E}-52$ \\
\hline
\end{tabular}

ent degrees of lip-like lateral petals, due to somaclonal variation. Mild change caused the lateral petals bulge slightly near the center, which was named semi-peloric flowers (Fig. 1D). In the severe case of somaclonal variation, enlarged central bulge of the lateral petals led the transition to lip-like, which was named peloric flowers (Fig. $1 \mathrm{~B}, \mathrm{E}$, $\mathrm{G}, \mathrm{H})$. The degree of the peloric flower formation varies in different Phalaenopsis hybrids as shown in Fig. 1. In severe cases, peloric flowers lost their pollinia (Fig. 1E). When the peloric mutant was re-propagated by tissue culture, some clones may revert back to the wild type flower morphology, an indication of epigenetic changes. Since peloric or semi-peloric mutants share the same genetic background with the wild type of the same variety, we took the advantage to investigate the peloric mutants on molecular level by using cDNA-RAPD and suppression subtractive hybridization techniques.

\section{Differentially expressed ESTs by cDNA-RAPD}

Two hundred random primers obtained from Operon (Operon Technologies, Inc., Alameda, CA), including OPAA01-20, OPB01-20, OPD01-20, OPE01-20, OPF0120, OPT01-20, OPW01-20, OPX01-20, OPY01-20 and OPZ01-20, were used to amplify cDNAs from peloric and wild type flower buds as well as leaves. No PCR products were observed among 45 primers. Products from other 35 primers showed no difference in amplified DNA fragments. The remaining 120 primers produced a total of 510 differ- ential DNA bands, including 93 from wild type flower buds, 366 from peloric flower buds, and 51 from leaves. Among those differentially expressed cDNAs, 191 bands were randomly picked for further characterization. Other bands were not included in the analysis due to noise background of their DNA sequences. After sequencing, only 90 inserts showed unambiguous sequence reading. The length of these cDNAs ranged from about 200 to $3000 \mathrm{bp}$. Those commonly expressed cDNAs were excluded for analysis. After searching against the GenBank by BlastX, the gene functions of the cDNA fragments were classified according to Bohnert et al. [33]. Among them, 28 cDNA clones were preferentially expressed in the wild type flower buds, and 24 expressed in the peloric mutants (Fig. 3A). Annotation of these ESTs was listed in Tab. 2 and Tab. 3. A majority of the cloned cDNA inserts belongs to the unknown function. Only a small proportion of ESTs encoded proteins involved in transcription, metabolism, signal transduction, etc. (Fig. 3A). The efficiency of the cDNARAPD approach seems to be low. Interestingly, transoposons and orchid virus (Cymbidium mosaic virus, CyMV; and Odontoglossum ringspot virus, ORSV) were only detected in the peloric mutants in this experiment (Fig. 3A, Tab. 3).

When transcripts of peloric flower buds were compared to that of the leaves in the same mutant, 38 ESTs were preferentially expressed in the flowers (Fig. 3B). Again, most of the ESTs (68.4\%) had no known function when searched against the GenBank (Tab. 4). One of the 
Tab. 3 Homology search of ESTs specifically enriched in mutant flowers by cDNA-RAPD flower-flower assay

\begin{tabular}{|c|c|c|c|}
\hline Clone ID & Description $^{\mathbf{a}}$ & Score (bits) ${ }^{b}$ & E value $^{c}$ \\
\hline LAA10M-20(5) & unknown protein [Arabidopsis thaliana] & 36.6 & 0.72 \\
\hline LAA15M-30(47) & TEM-93 ES-beta-lactamase [Escherichia coli] & 389 & e-107 \\
\hline LOPW02M-4-1(7) & Unknown protein $[$ Arabidopsis thaliana $]$ & 109 & $2.00 \mathrm{E}-32$ \\
\hline LOPW02M-4-2(9) & zinc finger protein $[$ Schizosaccharomyces pombe $]$ & 31.6 & 9.2 \\
\hline LOPW02M-4-3(11) & $\begin{array}{l}\text { hypothetical protein } 1 \text { - potato retrotransposon Tst } 1 \\
\text { [Solanum tuberosum] }\end{array}$ & 48.5 & $6.00 \mathrm{E}-05$ \\
\hline LOPW05M-10(13) & En/Spm-like transposon-like protein [Oryza sativa $]$ & 87.4 & $3.00 \mathrm{E}-21$ \\
\hline LOPW06M-12-1(23) & ORF2 [Porcine adenovirus 4] & 33.1 & 3.2 \\
\hline LOPW06M-12-2(25) & putative reverse transcriptase [Anopheles gambiae] & 57.8 & $1.00 \mathrm{E}-07$ \\
\hline LOPW06M-12-3(27) & no hit & - & - \\
\hline LOPW13M-26(41) & RF4 protein - yeast plasmid & 37.7 & 0.13 \\
\hline LOPW19M-38(46) & putative $\mathrm{ABC}$ transporter protein $[$ Oryza sativa $]$ & 287 & $2.00 \mathrm{E}-78$ \\
\hline OPT01M-42-2 & $\begin{array}{l}\text { hypothetical protein } \sim \text { similar to Arabidopsis thaliana } \\
\text { [Oryza sativa] }\end{array}$ & 118 & $8.00 \mathrm{E}-26$ \\
\hline OРТ05M-50 & putative WD-repeat protein [Arabidopsis thaliana] & 189 & $5.00 \mathrm{E}-50$ \\
\hline OPW01M-2(4) & unknown protein [Arabidopsis thaliana] & 99 & $5.00 \mathrm{E}-20$ \\
\hline OPW04M-8-2 & putative cytochrome c oxidase subunit [Arabidopsis thaliana] & 42.4 & 0.002 \\
\hline OPW07M-14 & VMP-like sequence protein VlsE [Borrelia burgdorferi] & 33.5 & 2.6 \\
\hline OPW18M-36-2 & RNA dependent RNA polymerase [Cymbidium mosaic virus] & 293 & $2.00 \mathrm{E}-79$ \\
\hline OPY06M-12(1) & triple gene block 2 [Cymbidium mosaic virus] & 167 & $4.00 \mathrm{E}-45$ \\
\hline OPY09M-18-2 & $183 \mathrm{kda}$ protein [Odontoglossum ringspot virus] & 140 & $5.00 \mathrm{E}-33$ \\
\hline ZOPAA01M-2(72) & RNA dependent RNA polymerase [Cymbidium mosaic virus] & 571 & e-162 \\
\hline ZOPAA01N-1(67) & F6N18.13 [Arabidopsis thaliana $]$ & 123 & $6.00 \mathrm{E}-28$ \\
\hline ZOPAA09N-17(85) & hypothetical protein [Plasmodium falciparum 3D7] & 34.3 & 0.45 \\
\hline ZOPAA14N-27(57) & hypothetical protein [Plasmodium falciparum 3D7] & 34.3 & 0.38 \\
\hline ZOPAA $17 \mathrm{~N}-33(51)$ & putative lipoxygenase [Oryza sativa] & 144 & $4.00 \mathrm{E}-34$ \\
\hline ZOPB10N-59(27) & p55 [Theileria orientalis $]$ & 34.3 & 0.35 \\
\hline ZOPB12N-63-2(29) & no hit & - & - \\
\hline ZOPB17N-73-1(47) & putative ankyrin $[$ Arabidopsis thaliana $]$ & 205 & $8.00 \mathrm{E}-55$ \\
\hline ZOPB18N-75(43) & Putative DEAD/DEAH box RNA helicase protein [Oryza sativa] & 308 & $5.00 \mathrm{E}-83$ \\
\hline
\end{tabular}

${ }^{a}$ Sequence description of the highest scoring alignments described by one line summaries.

${ }^{b}$ Scores (bits) assigned to an alignment calculated by summing the scores normalizing with the statistical variables for each position in the alignment.

${ }^{c}$ Expect (E) value describes the statistical significance threshold for reporting matches against database sequences.

ESTs, 607FF03-2, shows homology to MtN3 of the nodules of Medicago truncatula [35] and the NEC1 of Petunia hybrida [36]. $N E C l$ was specifically expressed in the nectary of the Petunia flowers [36].

Among the identified clones by cDNA-RAPD, most of the ESTs belong to the unknown protein category, partially contributed by unknown genome information of orchid and the incomplete ESTs sequences. Some ESTs were probably representing genes involved in signal transduction, protein-protein interactions and transcription regulation, such as cyclophylin, putative ankyrin [37], auxin-related dual specificity cytosolic kinase, putative DEAD/DEAH box RNA helicase, putative WD-repeat protein, and DNA binding protein TGAla (Tab. 2, 3). The RNA dependent RNA polymerase of CyMV, as well as several classes of retroelements or transposon has also been detected several times in the peloric flowers (Tab. 3, 4).

\section{Differentially expressed ESTs by SSH}

The forward subtractive cloning strategy of SSH (wild type flower buds as driver and peloric mutant as tester) generated 181 clones, and reverse subtractive SSH generated 104 clones (Fig. 3C). The highest percentage in the subtracted clones from both forward and reverse SSH was the unknown EST clones. Among them, 28.1\% were from the wild type flower buds, while only $3.5 \%$ from the peloric flower buds (Fig. 3C). EST clones responsible for metabolism, cell growth, signal transduction and transcription were present mainly in the wild type (Tab. 5), indicating the biased transcript expression due to either epige- 
Tab. 4 Homology search of ESTs enriched in peloric flower buds in cDNA-RAPD flower-leaf assay

\begin{tabular}{|c|c|c|c|}
\hline Clone ID & Description $^{a}$ & Score (bits) ${ }^{b}$ & E value \\
\hline 607FD02 & Hypothetical protein [Sulfolobus solfataricus] & 34.7 & 3.2 \\
\hline 607FD03 & putative polyprotein [Zea mays] & 47 & $4.00 \mathrm{E}-04$ \\
\hline 607FD04 & putative gag-pol precursor [Oryza sativa] & 59.3 & $3.00 \mathrm{E}-08$ \\
\hline 607FD05 & P0592C06.18 [Oryza sativa $]$ & 56.6 & $3.00 \mathrm{E}-07$ \\
\hline 607FD05(18) & hypothetical protein 2 - potato transposon Tst 1 & 64.3 & $2.00 \mathrm{E}-09$ \\
\hline 607FD07-1 & hypothetical protein FLJ10587 [Homo sapiens] & 105 & $9.00 \mathrm{E}-22$ \\
\hline 607FD07-2 & hypothetical protein [Neurospora crassa] & 33.5 & 0.67 \\
\hline 607FD08 & hypothetical protein [Chlamydia trachomatis] & 33.9 & 1.7 \\
\hline 607FD11 & unknown protein $[$ Arabidopsis thaliana $]$ & 30 & 9.1 \\
\hline 607FD12 & Putative retroelement $[$ Oryza sativa $]$ & 89.4 & $8.00 \mathrm{E}-17$ \\
\hline 607FD18-2 & glyoxalase I, putative (lactoylglutathione lyase) [Arabidopsis thaliana] & 102 & $1.00 \mathrm{E}-21$ \\
\hline 607FD20-2 & extracellular protein [Lactobacillus plantarum WCFS1] & 40.4 & 0.037 \\
\hline 607FE01 & hypothetical protein 3 - potato transposon Tst1 & 55.1 & 4.00E-07 \\
\hline 607FE03 & putative non-LTR retroelement reverse transcriptase [Arabidopsis thaliana] & 61.6 & $2.00 \mathrm{E}-10$ \\
\hline 607FE06-1 & hypothetical protein [Methanosarcina barkeri] & 35.4 & 1 \\
\hline 607FE06-2 & NBS/LRR resistance protein-like protein [Capsicum annuum] & 44.3 & $1.00 \mathrm{E}-09$ \\
\hline 607FE07 & PDR-like ABC transporter [Oryza sativa] & 437 & e-121 \\
\hline 607FE09-1 & En/Spm-like transposon-like protein [Oryza sativa] & 116 & $1.00 \mathrm{E}-38$ \\
\hline 607FE09-2 & $\begin{array}{l}\text { 2,3-bisphosphoglycerate-independent phosphoglycerate mutase } \\
\text { [Geobacillus stearothermophilus] }\end{array}$ & 35 & 1 \\
\hline 607FE09-3 & hypothetical protein $[$ Oryza sativa $]$ & 43.5 & $1.00 \mathrm{E}-05$ \\
\hline 607FE11 & hypothetical protein [Plasmodium falciparum 3D7] & 35 & 1 \\
\hline 607FF03-2 & MtN3-like protein [Arabidopsis thaliana] & 167 & $1.00 \mathrm{E}-40$ \\
\hline 607FF08 & $\begin{array}{l}\text { similar to Thyroxine-binding globulin precursor (T4-binding globulin) } \\
\text { [Homo sapiens] }\end{array}$ & 32 & 9.3 \\
\hline $607 F F 09$ & olfactory receptor MOR196-4 [Mus musculus $]$ & 32 & 6.4 \\
\hline $607 \mathrm{FF} 12$ & $\begin{array}{l}\text { guanosine-3',5'-bis(diphosphate) 3'- pyrophosphohydrolase (spoT) } \\
{[\text { Mycoplasma genitalium] }}\end{array}$ & 32.3 & 6.5 \\
\hline $607 \mathrm{FF} 13$ & putative protein $[$ Arabidopsis thaliana $]$ & 300 & $2.00 \mathrm{E}-80$ \\
\hline 607FW04 & putative amidase $[$ Arabidopsis thaliana $]$ & 57.4 & $1.00 \mathrm{E}-14$ \\
\hline 607FW06-1 & putative non-LTR retroelement reverse transcriptase [Arabidopsis thaliana] & 46.2 & 4.00E-04 \\
\hline 607FW06-2 & alpha 1B-glycoprotein [Homo sapiens] & 31.6 & 3.3 \\
\hline 607FW07-1 & hypothetical malaria antigen [Plasmodium falciparum 3D7] & 37 & 0.18 \\
\hline 607FW07-2 & $\begin{array}{l}\text { DNaJ domain (prokaryotic heat shock protein) DNJ-5 (dnj-5) } \\
\text { [Caenorhabditis elegans] }\end{array}$ & 33.9 & 0.49 \\
\hline 607FW09-2 & hypothetical protein[Arabidopsis thaliana] & 230 & $8.00 \mathrm{E}-60$ \\
\hline 607FW11 & no hit & - & - \\
\hline 607FW16-2 & unnamed protein product [Homo sapiens] & 35.8 & 0.15 \\
\hline 607FW19-2 & threonyl-tRNA synthetase [Oryza sativa] & 568 & e-161 \\
\hline 607FX01-1 & $\mathrm{NIb}$ protein [Potato virus $\mathrm{A}]$ & 33.5 & 4.5 \\
\hline 607FX01-2 & no hit & - & - \\
\hline 607FX06 & putative protein [Arabidopsis thaliana] & 239 & $2.00 \mathrm{E}-62$ \\
\hline ZOPAA03M-6(81) & [Anopheles gambiae str. PEST] & 29.6 & 8.9 \\
\hline ZOPAA11M-22(108) & $\begin{array}{l}\text { similar to cyclin-dependent kinase-like } 1 \text { (CDC2-related kinase) } \\
\text { [Mus musculus] [Rattus norvegicus] }\end{array}$ & 30.4 & 5.4 \\
\hline ZOPAA12M-24(65) & cyclophylin-like protein $[$ Arabidopsis thaliana $]$ & 153 & $2.00 \mathrm{E}-36$ \\
\hline ZOPB10M-60-2(1) & putative auxin-regulated dual specificity cytosolic kinase [Oryza sativa] & 125 & $1.00 \mathrm{E}-28$ \\
\hline
\end{tabular}

\footnotetext{
${ }^{a}$ Sequence description of the highest scoring alignments described by one line summaries

${ }^{\mathrm{b}} \mathrm{Scores}$ (bits) assigned to an alignment calculated by summing the scores normalizing with the statistical variables for each position in the alignment.

${ }^{\mathrm{c}}$ Expect (E) value describes the statistical significance threshold for reporting matches against database sequences.
} 
Tab. 5 Annotation of cDNA clones enriched in wildtype flower buds from SSH flower-flower analysis

\begin{tabular}{|c|c|c|c|}
\hline Clone ID & Description $^{a}$ & Score(bits) ${ }^{\mathrm{b}}$ & E value ${ }^{c}$ \\
\hline NP-1 & essential protein for meiotic synapsis [Oryza sativa (japonica cultivar-group)] & 86.3 & $9.00 \mathrm{E}-17$ \\
\hline NP-2 & unspecific monooxygenase (EC 1.14.14.1) - common tobacco & 140 & $6.00 \mathrm{E}-49$ \\
\hline NP-3 & hypothetical protein [Oryza sativa (japonica cultivar-group)] & 68.2 & $3.00 \mathrm{E}-11$ \\
\hline NP-4 & probable cytochrome P450 monooxygenase - maize (fragment) & 129 & $5.00 \mathrm{E}-48$ \\
\hline NP-5 & No significant similarity found. & - & - \\
\hline NP-6 & No significant similarity found. & - & - \\
\hline NP-7 & histone acetyltransferase HAT B [Arabidopsis thaliana] & 100 & $3.00 \mathrm{E}-41$ \\
\hline NP-8 & P0434B04.3 [Oryza sativa (japonica cultivar-group)] & 92.8 & $7.00 \mathrm{E}-18$ \\
\hline NP-9 & F2E2.13 [Arabidopsis thaliana $]$ & 115 & $3.00 \mathrm{E}-25$ \\
\hline NP-10 & 3-dehydroquinate synthase (EC 4.2.3.4) - [Emericella nidulans] & 35 & 0.24 \\
\hline NP-11 & CG3231-PA [Drosophila melanogaster] & 57.4 & $1.00 \mathrm{E}-07$ \\
\hline NP-12 & hypothetical protein - Arabidopsis thaliana & 57.4 & $6.00 \mathrm{E}-08$ \\
\hline NP-13 & No hit & - & - \\
\hline NP-14 & zinc-finger protein [Oryza sativa (indica cultivar-group)] & 57 & $7.00 \mathrm{E}-08$ \\
\hline NP-15 & cytochrome P450 monooxygenase [Zea mays] & 149 & $7.00 \mathrm{E}-54$ \\
\hline NP-16 & putative condensin complex subunit [Oryza sativa (japonica cultivar-group)] & 40 & 0.01 \\
\hline NP-17 & AKIN gamma [Medicago truncatula] & 47.8 & $5.00 \mathrm{E}-05$ \\
\hline NP-18 & unspecific monooxygenase (EC 1.14.14.1) - common tobacco & 139 & $6.00 \mathrm{E}-49$ \\
\hline NP-19 & essential protein for meiotic synapsis [Oryza sativa (japonica cultivar-group)] & 194 & $1.00 \mathrm{E}-48$ \\
\hline NP-21 & unknown protein [Oryza sativa (japonica cultivar-group)] & 322 & $2.00 \mathrm{E}-87$ \\
\hline NP-22 & essential protein for meiotic synapsis [Oryza sativa (japonica cultivar-group)] & 174 & $2.00 \mathrm{E}-42$ \\
\hline NP-23 & OSJNBa0033G05.19 [Oryza sativa (japonica cultivar-group)] & 56.6 & $1.00 \mathrm{E}-07$ \\
\hline NP-24 & putative GTP-binding protein [Oryza sativa (japonica cultivar-group)] & 178 & $5.00 \mathrm{E}-44$ \\
\hline NP-25 & phragmoplastin 5 - soybean & 335 & $2.00 \mathrm{E}-91$ \\
\hline NP-26 & cytochrome P450 family [Arabidopsis thaliana $]$ & 181 & $4.00 \mathrm{E}-45$ \\
\hline NP-27 & ribosomal protein S8 - Plasmodium falciparum plastid & 31.2 & 4.4 \\
\hline NP-28 & AKIN gamma $[$ Medicago truncatula $]$ & 47.8 & $5.00 \mathrm{E}-05$ \\
\hline NP-29 & essential protein for meiotic synapsis [Oryza sativa (japonica cultivar-group)] & 86.3 & $9.00 \mathrm{E}-17$ \\
\hline NP-30 & tubulin folding cofactor B [Arabidopsis thaliana] & 242 & $2.00 \mathrm{E}-63$ \\
\hline NP-31 & transcription factor PCF5 [Oryza sativa (japonica cultivar-group)]; TCP & 36.6 & 0.098 \\
\hline NP-32 & unknown [Oryza sativa (japonica cultivar-group)] & 94 & $9.00 \mathrm{E}-19$ \\
\hline NP-33 & RNA dependent RNA polymerase [Cymbidium mosaic virus] & 297 & $4.00 \mathrm{E}-80$ \\
\hline NP-34 & unknown [Oryza sativa (japonica cultivar-group)] & 94 & $9.00 \mathrm{E}-19$ \\
\hline NP-36 & expressed integral membrane protein common family [Arabidopsis thaliana] & 56 & $1.00 \mathrm{E}-07$ \\
\hline NP-37 & $\begin{array}{l}\text { mitochondrial ribosomal protein } \mathrm{S} 2 \text {; mitochondrial } 28 \mathrm{~S} \text { ribosomal protein } \mathrm{S} 2 \\
\text { [Homo sapiens]. }\end{array}$ & 30.4 & 7.8 \\
\hline NP-38 & $\begin{array}{l}\text { Proteasome subunit alpha type } 7 \text { (20S proteasome alpha subunit D) } \\
\text { (20S proteasome subunit alpha- } 4)\end{array}$ & 143 & $8.00 \mathrm{E}-34$ \\
\hline NP-39 & $\begin{array}{l}\text { Proteasome subunit alpha type } 7 \text { (20S proteasome alpha subunit D) } \\
(20 \mathrm{~S} \text { proteasome subunit alpha- } 4)\end{array}$ & 143 & $8.00 \mathrm{E}-34$ \\
\hline NP-40 & expressed integral membrane protein common family [Arabidopsis thaliana] & 56 & $1.00 \mathrm{E}-07$ \\
\hline NP-41 & $\begin{array}{l}\text { 26S proteasome non-ATPase regulatory subunit } 6 \\
\text { (26S proteasome regulatory particle non-ATPase subunit 7) (OsRPN7) }\end{array}$ & 226 & $1.00 \mathrm{E}-58$ \\
\hline NP-42 & cytosolic glutamine synthetase [Brassica napus] & 202 & $1.00 \mathrm{E}-51$ \\
\hline NP-43 & No hit & - & - \\
\hline NP-44 & No hit & - & - \\
\hline NP-45 & No hit & - & - \\
\hline NP-46 & catalase $[$ Prunus persica $]$ & 405 & $\mathrm{e}-112$ \\
\hline NP-48 & catalase $[$ Prunus persica $]$ & 407 & e-112 \\
\hline NP-49 & $\begin{array}{l}\text { Proteasome subunit alpha type } 7 \text { ( } 20 \mathrm{~S} \text { proteasome alpha subunit D) } \\
\text { (20S proteasome subunit alpha- } 4 \text { ) }\end{array}$ & 143 & $8.00 \mathrm{E}-34$ \\
\hline NP-50 & No hit & - & - \\
\hline NP-51 & ribosomal protein S7 [Triticum aestivum] & 53.9 & $7.00 \mathrm{E}-07$ \\
\hline NP-52 & OSJNBb0093G06.14 [Oryza sativa (japonica cultivar-group)] & 191 & $2.00 \mathrm{E}-48$ \\
\hline
\end{tabular}


Tab. 5 Annotation of cDNA clones enriched in wildtype flower buds from SSH flower-flower analysis (continued-1)

\begin{tabular}{|c|c|c|c|}
\hline Clone ID & Description $^{\mathbf{a}}$ & Score(bits) ${ }^{b}$ & E value $^{\mathrm{c}}$ \\
\hline NP-54 & catalase $[$ Prunus persica $]$ & 432 & e-120 \\
\hline NP-55 & betaine-aldehyde dehydrogenase, putative (BADH) [Arabidopsis thaliana $]$ & 223 & $1.00 \mathrm{E}-57$ \\
\hline NP-56 & catalase $[$ Prunus persica $]$ & 421 & e-116 \\
\hline NP-57 & No hit & - & - \\
\hline NP-58 & No hit & - & - \\
\hline NP-62 & hypothetical protein [Arabidopsis thaliana] & 67 & $2.00 \mathrm{E}-10$ \\
\hline NP-63 & hypothetical protein [Arabidopsis thaliana] & 67 & $2.00 \mathrm{E}-10$ \\
\hline NP-64 & RISBZ4 [Oryza sativa $]$ & 157 & $4.00 \mathrm{E}-38$ \\
\hline NP-66 & pyruvate dehydrogenase kinase isoform 1; PDK1 [Zea mays] & 326 & $2.00 \mathrm{E}-98$ \\
\hline NP-68 & CG1 protein [Plasmodium falciparum $]$ & 30.4 & 6.2 \\
\hline NP70 & Putative RNA-binding protein [Oryza sativa] & 98.2 & $3.00 \mathrm{E}-20$ \\
\hline NP71 & putative senescence-associated protein [Pisum sativum] & 130 & $4.00 \mathrm{E}-49$ \\
\hline NP72 & essential protein for meiotic synapsis [Oryza sativa] & 172 & $4.00 \mathrm{E}-42$ \\
\hline NP73 & putative condensin complex subunit [Oryza sativa] & 40 & 0.01 \\
\hline NP76 & pectin methyl esterase [Solanum tuberosum $]$ & 52 & $2.00 \mathrm{E}-06$ \\
\hline NP77 & ER lumen retaining receptor (HDEL receptor), putative [Arabidopsis thaliana] & 169 & $1.00 \mathrm{E}-41$ \\
\hline NP78 & cytochrome P450 like_TBP [Nicotiana tabacum $]$ & 136 & 7.00E-48 \\
\hline NP79 & cytochrome P450 like_TBP [Nicotiana tabacum $]$ & 136 & $6.00 \mathrm{E}-48$ \\
\hline NP80 & B1139B11.7 [Oryza sativa , phosphoesterase family [Arabidopsis thaliana] & 130 & $4.00 \mathrm{E}-30$ \\
\hline NP81 & transmembrane protein FT27/PFT27-like [Arabidopsis thaliana] & 110 & $5.00 \mathrm{E}-24$ \\
\hline NP82 & cytochrome P450 like_TBP [Nicotiana tabacum $]$ & 136 & $6.00 \mathrm{E}-48$ \\
\hline NP83 & putative senescence-associated protein [Pisum sativum] & 248 & $1.00 \mathrm{E}-64$ \\
\hline NP85 & AKIN gamma $[$ Medicago truncatula $]$ & 49.3 & $2.00 \mathrm{E}-05$ \\
\hline NP87 & putative CER1 [Oryza sativa (japonica cultivar-group)] & 242 & $3.00 \mathrm{E}-63$ \\
\hline NP88 & cyclin family $[$ Arabidopsis thaliana $]$ & 188 & $9.00 \mathrm{E}-47$ \\
\hline NP89 & putative peptide transporter [Oryza sativa (japonica cultivar-group)] & 130 & $5.00 \mathrm{E}-30$ \\
\hline NP90 & GTP pyrophosphokinase [Bacillus anthracis str. Ames] & 45.4 & $5.00 \mathrm{E}-04$ \\
\hline NP91 & No hit & - & - \\
\hline NP92 & Putative RNA-binding protein [Oryza sativa (japonica cultivar-group)] & 117 & $4.00 \mathrm{E}-26$ \\
\hline NP93 & No hit & - & - \\
\hline NP94 & ER lumen retaining receptor (HDEL receptor), putative [Arabidopsis thaliana] & 171 & $5.00 \mathrm{E}-42$ \\
\hline NP95 & putative condensin complex subunit [Oryza sativa (japonica cultivar-group)] & 42.4 & 0.002 \\
\hline NP96 & No hit & - & - \\
\hline NP97 & OSJNBa0027G07.12 [Oryza sativa (japonica cultivar-group)] & 54.7 & $6.00 \mathrm{E}-07$ \\
\hline NP98 & unspecific monooxygenase (EC 1.14.14.1) - common tobacco & 137 & $2.00 \mathrm{E}-48$ \\
\hline NP99 & putative senescence-associated protein [Pisum sativum] & 244 & $1.00 \mathrm{E}-63$ \\
\hline NP100 & DNA cytosine methyltransferase MET2a [Zea mays] & 283 & $3.00 \mathrm{E}-75$ \\
\hline NP101 & hypothetical protein [Plasmodium yoelii yoelii] & 33.1 & 1.1 \\
\hline NP102 & P0701D05.20 [Oryza sativa (japonica cultivar-group)] & 204 & $7.00 \mathrm{E}-52$ \\
\hline NP103 & expressed protein $[$ Arabidopsis thaliana $]$ & 168 & $8.00 \mathrm{E}-41$ \\
\hline NP104 & cytochrome P450 family [Arabidopsis thaliana] & 181 & $5.00 \mathrm{E}-45$ \\
\hline NP105 & unspecific monooxygenase (EC 1.14.14.1) - common tobacco & 137 & $5.00 \mathrm{E}-48$ \\
\hline NP106 & OSJNBa0043L24.13 [Oryza sativa (japonica cultivar-group)] & 86.7 & $8.00 \mathrm{E}-17$ \\
\hline NP107 & $\begin{array}{l}\text { putative eukaryotic translation initiation factor } 6 \text { [Oryza sativa } \\
\text { (japonica cultivar-group)] }\end{array}$ & 94.7 & $4.00 \mathrm{E}-19$ \\
\hline NP108 & Putative RNA-binding protein [Oryza sativa (japonica cultivar-group)] & 100 & $2.00 \mathrm{E}-22$ \\
\hline NP110 & hypothetical protein [Nicotiana tabacum] & 209 & $3.00 \mathrm{E}-53$ \\
\hline NP111 & essential protein for meiotic synapsis [Oryza sativa (japonica cultivar-group)] & 191 & $8.00 \mathrm{E}-48$ \\
\hline NP112 & putative condensin complex subunit [Oryza sativa (japonica cultivar-group)] & 42.4 & 0.002 \\
\hline NP114 & putative PHD-finger protein [Oryza sativa (japonica cultivar-group)] & 177 & $2.00 \mathrm{E}-43$ \\
\hline NP115 & DYAD [Arabidopsis thaliana $]$ & 82 & $3.00 \mathrm{E}-15$ \\
\hline NP116 & P0434B04.3 [Oryza sativa (japonica cultivar-group)] & 90.5 & $4.00 \mathrm{E}-17$ \\
\hline NP117 & ZYG homolog [Homo sapiens $]$ & 31.2 & 4.2 \\
\hline NP118 & cytosolic class II low molecular weight heat shock protein [Prunus dulcis] & 141 & $1.00 \mathrm{E}-32$ \\
\hline
\end{tabular}


Tab. 5 Annotation of cDNA clones enriched in wildtype flower buds from SSH flower-flower analysis (continued-2)

\begin{tabular}{|c|c|c|c|}
\hline Clone ID & Description $^{\mathbf{a}}$ & Score(bits) ${ }^{\mathrm{b}}$ & E value ${ }^{c}$ \\
\hline NP119 & $\begin{array}{l}\text { putative phenylalanyl-tRNA synthetase alpha chain } \\
\text { [Oryza sativa (japonica cultivar-group)] }\end{array}$ & 62 & $2.00 \mathrm{E}-09$ \\
\hline NP120 & No hit & - & - \\
\hline NP121 & MNF13.29 unknown protein [Arabidopsis thaliana] & 67.8 & $2.00 \mathrm{E}-10$ \\
\hline NP123 & Putative RNA-binding protein [Oryza sativa (japonica cultivar-group)] & 117 & $3.00 \mathrm{E}-26$ \\
\hline NP124 & ER lumen retaining receptor (HDEL receptor), putative [Arabidopsis thaliana] & 171 & $5.00 \mathrm{E}-42$ \\
\hline NP126 & No hit & - & - \\
\hline NP129 & HAK4 [Oryza sativa $]$ & 261 & $3.00 \mathrm{E}-69$ \\
\hline NP131 & triple gene block 3 [Cymbidium mosaic virus] & 95.5 & $2.00 \mathrm{E}-19$ \\
\hline NP132 & receptor-related protein kinase, ERECTA [Arabidopsis thaliana] & 176 & $5.00 \mathrm{E}-44$ \\
\hline NP135 & Putative quinone oxidoreductase [Oryza sativa] & 158 & $2.00 \mathrm{E}-38$ \\
\hline NP136 & zinc-finger protein [Oryza sativa (indica cultivar-group)] & 55.1 & $3.00 \mathrm{E}-07$ \\
\hline NP137 & unspecific monooxygenase (EC 1.14.14.1) - common tobacco & 140 & $3.00 \mathrm{E}-49$ \\
\hline NP138 & NADP dependent malic enzyme [Oryza sativa (japonica cultivar-group)] & 229 & $7.00 \mathrm{E}-60$ \\
\hline NP139 & ATP citrate lyase $[$ Arabidopsis thaliana $]$ & 252 & $7.00 \mathrm{E}-67$ \\
\hline NP140 & hypothetical protein [Plasmodium falciparum 3D7] & 32.3 & 4.7 \\
\hline NP141 & calmodulin $1[$ Brassica oleracea $]$ & 152 & $2.00 \mathrm{E}-36$ \\
\hline NP143 & putative esterase [Oryza sativa (japonica cultivar-group)] & 155 & $1.00 \mathrm{E}-37$ \\
\hline NP146 & SNF1-related protein kinase [Hordeum vulgare subsp. vulgare] & 112 & $1.00 \mathrm{E}-40$ \\
\hline NP147 & lipid transfer protein precursor [Davidia involucrata] & 106 & $1.00 \mathrm{E}-22$ \\
\hline NP148 & unknown protein $[$ Oryza sativa] & 321 & $1.00 \mathrm{E}-92$ \\
\hline NP150 & unspecific monooxygenase (EC 1.14.14.1) - common tobacco & 137 & $1.00 \mathrm{E}-47$ \\
\hline NP151 & F18014.34 [Arabidopsis thaliana $]$ & 221 & $7.00 \mathrm{E}-57$ \\
\hline NP153 & essential protein for meiotic synapsis [Oryza sativa (japonica cultivar-group)] & 52 & $2.00 \mathrm{E}-06$ \\
\hline NP154 & unspecific monooxygenase (EC 1.14.14.1) - common tobacco & 139 & $8.00 \mathrm{E}-49$ \\
\hline NP156 & expressed protein [Arabidopsis thaliana] & 67.8 & $3.00 \mathrm{E}-10$ \\
\hline NP157 & No hit & - & - \\
\hline NP158 & No hit & - & - \\
\hline NP159 & No hit & - & - \\
\hline NP161 & coat protein - Cymbidium mosaic virus & 178 & $4.00 \mathrm{E}-44$ \\
\hline NP162 & putative condensin complex subunit [Oryza sativa (japonica cultivar-group)] & 40 & 0.01 \\
\hline NP163 & OSJNBa0032F06.16 [Oryza sativa (japonica cultivar-group)] & 161 & $3.00 \mathrm{E}-39$ \\
\hline NP164 & putative senescence-associated protein [Pisum sativum] & 207 & $5.00 \mathrm{E}-54$ \\
\hline NP165 & essential protein for meiotic synapsis [Oryza sativa (japonica cultivar-group)] & 244 & $5.00 \mathrm{E}-64$ \\
\hline NP168 & No hit & - & - \\
\hline NP170 & similar to KIAA1205 protein [Homo sapiens] & 34.7 & 2.2 \\
\hline NP171 & hypothetical protein At2g29670 [imported] - Arabidopsis thaliana & 136 & $4.00 \mathrm{E}-31$ \\
\hline NP172 & No hit & - & - \\
\hline NP173 & No hit & - & - \\
\hline NP174 & No hit & - & - \\
\hline NP175 & $60 \mathrm{~S}$ ribosomal protein L17 [Oryza sativa] & 122 & $1.00 \mathrm{E}-27$ \\
\hline NP176 & No hit & - & - \\
\hline NP177 & unspecific monooxygenase (EC 1.14.14.1) - common tobacco & 136 & $7.00 \mathrm{E}-48$ \\
\hline NP178 & CG3231-PA [Drosophila melanogaster] & 57.4 & $1.00 \mathrm{E}-07$ \\
\hline NP179 & putative senescence-associated protein [Pisum sativum] & 244 & $1.00 \mathrm{E}-63$ \\
\hline NP180 & putative WD repeat protein $[$ Oryza sativa] & 181 & $6.00 \mathrm{E}-45$ \\
\hline NP181 & putative auxin-repressed protein [Prunus armeniaca $]$ & 80.5 & $1.00 \mathrm{E}-14$ \\
\hline NP182 & unspecific monooxygenase (EC 1.14.14.1) - common tobacco & 136 & $6.00 \mathrm{E}-48$ \\
\hline NP185 & F20D23.20 protein - Arabidopsis thaliana & 190 & $1.00 \mathrm{E}-47$ \\
\hline NP186 & F20D23.20 protein - Arabidopsis thaliana & 190 & $1.00 \mathrm{E}-47$ \\
\hline NP187 & putative peptide transporter [Oryza sativa] & 130 & $5.00 \mathrm{E}-30$ \\
\hline NP188 & unknown $[$ Arabidopsis thaliana $]$ & 247 & $2.00 \mathrm{E}-64$ \\
\hline NP189 & hypothetical protein [Oenothera elata subsp. hookeri] & 36.2 & 0.25 \\
\hline NP191 & probable cytochrome P450 monooxygenase - maize (fragment) & 129 & $8.00 \mathrm{E}-48$ \\
\hline
\end{tabular}


Tab. 5 Annotation of cDNA clones enriched in wildtype flower buds from SSH flower-flower analysis (continued-3)

\begin{tabular}{|c|c|c|c|}
\hline Clone ID & Description $^{\mathbf{a}}$ & Score(bits) ${ }^{b}$ & E value \\
\hline NP192 & putative WD repeat protein [Oryza sativa (japonica cultivar-group)] & 181 & $6.00 \mathrm{E}-45$ \\
\hline NP193 & ring finger protein (2G644) [Caenorhabditis elegans] & 32.7 & 2 \\
\hline NP194 & putative RNA-binding protein [Oryza sativa] & 203 & $6.00 \mathrm{E}-52$ \\
\hline NP195 & metallothionein-like protein type 2 [Narcissus pseudonarcissus] & 87.8 & $8.00 \mathrm{E}-17$ \\
\hline NP196 & essential protein for meiotic synapsis [Oryza sativa] & 86.3 & $2.00 \mathrm{E}-16$ \\
\hline NP197 & L-galactono-1,4-lactone dehydrogenase, putative [Arabidopsis] & 287 & $2.00 \mathrm{E}-76$ \\
\hline NP198 & putative senescence-associated protein [Pisum sativum $]$ & 251 & $1.00 \mathrm{E}-65$ \\
\hline NP199 & transfactor-like [Oryza sativa] & 139 & $2.00 \mathrm{E}-32$ \\
\hline NP200 & unknown protein [Oryza sativa] & 301 & $4.00 \mathrm{E}-81$ \\
\hline NP201 & putative cyclin Ia [Oryza sativa $]$ & 60.5 & $2.00 \mathrm{E}-08$ \\
\hline NP203 & essential protein for meiotic synapsis [Oryza sativa] & 86.3 & $9.00 \mathrm{E}-17$ \\
\hline NP205 & histone deacetylase [Solanum chacoense] & 36.6 & 0.34 \\
\hline NP206 & expressed protein [Arabidopsis thaliana] & 166 & $2.00 \mathrm{E}-40$ \\
\hline NP210 & unknown protein [Oryza sativa ] & 95.9 & $1.00 \mathrm{E}-19$ \\
\hline NP212 & OSJNBa0058K23.21 [Oryza sativa] & 130 & $3.00 \mathrm{E}-29$ \\
\hline NP213 & hypothetical protein $[$ Erwinia amylovora $]$ & 269 & $4.00 \mathrm{E}-71$ \\
\hline NP215 & putative senescence-associated protein [Pisum sativum] & 255 & $7.00 \mathrm{E}-67$ \\
\hline NP216 & phosphoesterase family $[$ Arabidopsis thaliana $]$ & 106 & $4.00 \mathrm{E}-22$ \\
\hline NP217 & putative ARP2/3 complex $20 \mathrm{kDa}$ subunit, 3'-partial [Oryza sativa] & 48.5 & $9.00 \mathrm{E}-05$ \\
\hline NP219 & putative senescence-associated protein [Pisum sativum] & 243 & $3.00 \mathrm{E}-63$ \\
\hline NP220 & Alpha-S1 casein precursor $[$ Sus scrofa $]$ & 33.1 & 1.1 \\
\hline NP221 & AKIN gamma [Medicago truncatula $]$ & 47.8 & $5.00 \mathrm{E}-05$ \\
\hline NP222 & hypothetical protein MG02240.4 [Magnaporthe grisea 70-15] & 33.1 & 1.1 \\
\hline NP223 & succinate dehydrogenase subunit 3 [Podophyllum peltatum] & 32.3 & 2.1 \\
\hline NP224 & putative senescence-associated protein [Pisum sativum $]$ & 245 & $8.00 \mathrm{E}-65$ \\
\hline NP226 & chaperonin, putative [Arabidopsis thaliana] & 338 & $8.00 \mathrm{E}-92$ \\
\hline
\end{tabular}

${ }^{\text {a }}$ Sequence description of the highest scoring alignments described by one line summaries

${ }^{\mathrm{b} S}$ Scores (bits) assigned to an alignment calculated by summing the scores normalizing with the statistical variables for each position in the alignment.

${ }^{c}$ Expect (E) value describes the statistical significance threshold for reporting matches against database sequences.

netic changes or virus infection. We observed 80 clones (28.1\%) of the ESTs, from peloric flower buds, belonging to the transcripts of the orchid virus, Cymbidium mosaic virus (CyMV). Almost the whole genome of the CyMV, including RNA replicase, RNA-dependent RNA polymerase, movement protein, triple gene blocks, and coat protein, was preferentially enriched in the peloric flower buds after SSH (Tab. 6). In order to overcome the surveillance of host cells by posttranscriptional gene silencing, tombusviruses may preferentially express gene products such as 19 protein to serve as a silencing suppressor so that virus population can be established in host cells [38]. The enriched virus in orchid tissues may also adopt similar strategy as tombusviruses to overcome the surveillance of host cells.

When the peloric flower buds were used as driver, and leaves of the same mutant as tester, 64 EST clones were enriched in the flower buds (Fig. 3D). Again, genes with unknown function and metabolism (such as tocopherol cyclase, polyamine oxidase, arginine decarboxylase, and pectinesterase, Tab. 7) were present in majority (37.5 and
$25 \%$, respectively). Two clones (D20, NP-31) containing TCP domain, which may play a role in floral symmetry [39-41], were detected in the peloric flower buds from the flower-to-leaves SSH (Tab. 7), as well as in the wild type from the flower-to-flower SSH (NP-31, Tab. 5), respectively.

Some other ESTs, involved in DNA methylation, chromatin remodeling and post-transcriptional regulation, such as DNA methyltransferase, histone acetyltransferase, ERECTA, and DEAD/DEAH RNA helicase, were preferentially up-expressed in wild type flower buds (Tab. 2, 5) in the wild type-flower/mutant-flower SSH. Thus the ESTs involved in epigenetic regulation are down regulated in the mutants, suggesting abnormal gene silencing in the mutants. Multiple copies of cDNA clones were observed in the SSH experiments, such as unspecific monooxygenase, proteasome subunit alpha type 7, cytochrome P450 likeTBP, RNA dependent RNA polymerase (CyMV), triple gene blocks, etc (Tab. 5, 6). Whether they belong to the real differentially expressed clones or due to background in- 
Tab. 6 Annotation of cDNA clones enriched in peloric flower buds from SSH flower-flower analysis

\begin{tabular}{|c|c|c|c|}
\hline Clone ID & Description $^{a}$ & Score(bits) ${ }^{b}$ & E value $^{\mathrm{c}}$ \\
\hline PN-1 & putative nucleic acid binding protein [Oryza sativa (japonica cultivar-group)] & 75.9 & $1.00 \mathrm{E}-13$ \\
\hline $\mathrm{PN}-2$ & triple gene block 1 [Cymbidium mosaic virus] & 161 & $2.00 \mathrm{E}-39$ \\
\hline $\mathrm{PN}-4$ & triple gene block 3 [Cymbidium mosaic virus] & 95.5 & $2.00 \mathrm{E}-19$ \\
\hline PN-6 & RNA dependent RNA polymerase [Cymbidium mosaic virus] & 398 & e-110 \\
\hline PN-7 & expressed protein [Arabidopsis thaliana] & 139 & $1.00 \mathrm{E}-32$ \\
\hline $\mathrm{PN}-8$ & OJ1136_A10.4 [Oryza sativa (japonica cultivar-group)] & 162 & $8.00 \mathrm{E}-40$ \\
\hline PN-9 & triple gene block 3 [Cymbidium mosaic virus] & 95.5 & $2.00 \mathrm{E}-19$ \\
\hline $\mathrm{PN}-10$ & triple gene block 3 [Cymbidium mosaic virus] & 95.5 & $2.00 \mathrm{E}-19$ \\
\hline PN-11 & RNA replicase [Cymbidium mosaic virus] & 407 & e-112 \\
\hline $\mathrm{PN}-12$ & RNA dependent RNA polymerase [Cymbidium mosaic virus] & 435 & e-121 \\
\hline PN-13 & RNA dependent RNA polymerase [Cymbidium mosaic virus] & 424 & e-118 \\
\hline $\mathrm{PN}-14$ & triple gene block 3 [Cymbidium mosaic virus] & 54.7 & 4.00E-07 \\
\hline $\mathrm{PN}-15$ & triple gene block 1 [Cymbidium mosaic virus] & 299 & $2.00 \mathrm{E}-80$ \\
\hline $\mathrm{PN}-16$ & $40 \mathrm{~S}$ ribosomal protein $\mathrm{S} 8$ & 146 & $7.00 \mathrm{E}-35$ \\
\hline PN-17 & unspecific monooxygenase (EC 1.14.14.1) - common tobacco & 137 & $3.00 \mathrm{E}-48$ \\
\hline $\mathrm{PN}-18$ & triple gene block 1 [Cymbidium mosaic virus] & 424 & e-118 \\
\hline PN-19 & putative protein [Arabidopsis thaliana $]$ & 259 & $2.00 \mathrm{E}-68$ \\
\hline PN-20 & triple gene block 1 [Cymbidium mosaic virus] & 336 & $2.00 \mathrm{E}-91$ \\
\hline PN-21 & MP1 [Cymbidium mosaic virus] & 131 & $3.00 \mathrm{E}-30$ \\
\hline $\mathrm{PN}-22$ & triple gene block 1 [Cymbidium mosaic virus] & 161 & $2.00 \mathrm{E}-39$ \\
\hline $\mathrm{PN}-23$ & triple gene block 3 [Cymbidium mosaic virus] & 95.5 & $2.00 \mathrm{E}-19$ \\
\hline $\mathrm{PN}-24$ & triple gene block 2 [Cymbidium mosaic virus] & 103 & $1.00 \mathrm{E}-21$ \\
\hline $\mathrm{PN}-25$ & triple gene block 1 [Cymbidium mosaic virus] & 241 & $1.00 \mathrm{E}-85$ \\
\hline $\mathrm{PN}-30$ & triple gene block 3 [Cymbidium mosaic virus] & 95.5 & $2.00 \mathrm{E}-19$ \\
\hline PN70 & putative senescence-associated protein [Pisum sativum] & 244 & $2.00 \mathrm{E}-63$ \\
\hline PN71 & triple gene block 2 [Cymbidium mosaic virus] & 112 & $2.00 \mathrm{E}-24$ \\
\hline PN72 & RNA dependent RNA polymerase [Cymbidium mosaic virus] & 293 & $6.00 \mathrm{E}-79$ \\
\hline PN73 & triple gene block 1 [Cymbidium mosaic virus] & 334 & $1.00 \mathrm{E}-90$ \\
\hline PN74 & RNA dependent RNA polymerase [Cymbidium mosaic virus] & 390 & e-107 \\
\hline PN75 & RNA dependent RNA polymerase [Cymbidium mosaic virus] & 241 & $3.00 \mathrm{E}-63$ \\
\hline PN76 & triple gene block 1 [Cymbidium mosaic virus] & 324 & $8.00 \mathrm{E}-88$ \\
\hline PN77 & OSJNBa0070C17.7 [Oryza sativa] & 63.9 & $2.00 \mathrm{E}-21$ \\
\hline PN78 & triple gene block 1 [Cymbidium mosaic virus] & 216 & $5.00 \mathrm{E}-55$ \\
\hline PN79 & RNA dependent RNA polymerase [Cymbidium mosaic virus] & 276 & $5.00 \mathrm{E}-73$ \\
\hline PN80 & hypothetical protein wali7 - wheat (fragment) & 183 & $6.00 \mathrm{E}-46$ \\
\hline PN81 & RNA dependent RNA polymerase [Cymbidium mosaic virus] & 285 & $2.00 \mathrm{E}-76$ \\
\hline PN82 & coat protein [Cymbidium mosaic virus] & 261 & $2.00 \mathrm{E}-69$ \\
\hline PN83 & RNA dependent RNA polymerase [Cymbidium mosaic virus] & 257 & e-111 \\
\hline PN84 & MP1 [Cymbidium mosaic virus] & 117 & $4.00 \mathrm{E}-26$ \\
\hline PN85 & triple gene block 3 [Cymbidium mosaic virus] & 94.4 & $4.00 \mathrm{E}-19$ \\
\hline PN86 & triple gene block 3 [Cymbidium mosaic virus] & 103 & $3.00 \mathrm{E}-21$ \\
\hline PN87 & chaperonin 60 alpha subunit [Canavalia lineata] & 70.9 & $6.00 \mathrm{E}-12$ \\
\hline PN88 & triple gene block 2 [Cymbidium mosaic virus] & 125 & $2.00 \mathrm{E}-28$ \\
\hline PN89 & RNA dependent RNA polymerase [Cymbidium mosaic virus] & 415 & e-115 \\
\hline PN90 & triple gene block 3 [Cymbidium mosaic virus] & 94.4 & $4.00 \mathrm{E}-19$ \\
\hline PN91 & MP1 [Cymbidium mosaic virus] & 131 & $3.00 \mathrm{E}-30$ \\
\hline PN92 & RNA dependent RNA polymerase [Cymbidium mosaic virus] & 425 & e-118 \\
\hline PN93 & triple gene block 1 [Cymbidium mosaic virus] & 324 & $1.00 \mathrm{E}-87$ \\
\hline PN94 & triple gene block 1 [Cymbidium mosaic virus] & 186 & $4.00 \mathrm{E}-46$ \\
\hline PN95 & unknown protein $[$ Arabidopsis thaliana $]$ & 64.3 & $1.00 \mathrm{E}-09$ \\
\hline PN96 & putative Rab geranylgeranyl transferase [Arabidopsis thaliana $]$ & 141 & $3.00 \mathrm{E}-33$ \\
\hline PN97 & triple gene block 3 [Cymbidium mosaic virus] & 94.4 & $4.00 \mathrm{E}-19$ \\
\hline PN98 & triple gene block 1 [Cymbidium mosaic virus] & 420 & e-116 \\
\hline PN99 & triple gene block 1 [Cymbidium mosaic virus] & 253 & $2.00 \mathrm{E}-81$ \\
\hline
\end{tabular}


Tab. 6 Annotation of cDNA clones enriched in peloric flower buds from SSH flower-flower analysis (continued-1)

\begin{tabular}{|c|c|c|c|}
\hline Clone ID & Description $^{\mathbf{a}}$ & Score $(\text { bits })^{b}$ & E value ${ }^{c}$ \\
\hline PN100 & triple gene block 1 [Cymbidium mosaic virus] & 263 & $1.00 \mathrm{E}-69$ \\
\hline PN101 & triple gene block 1 [Cymbidium mosaic virus] & 317 & $5.00 \mathrm{E}-88$ \\
\hline PN102 & coat protein [Cymbidium mosaic virus] & 83.6 & $7.00 \mathrm{E}-16$ \\
\hline PN103 & triple gene block 1 [Cymbidium mosaic virus] & 289 & $1.00 \mathrm{E}-80$ \\
\hline PN104 & triple gene block 1 [Cymbidium mosaic virus] & 292 & $1.00 \mathrm{E}-78$ \\
\hline PN105 & triple gene block 2 [Cymbidium mosaic virus] & 110 & $4.00 \mathrm{E}-24$ \\
\hline PN106 & triple gene block 2 [Cymbidium mosaic virus] & 110 & $4.00 \mathrm{E}-24$ \\
\hline PN107 & proton pump -related [Arabidopsis thaliana] & 132 & $2.00 \mathrm{E}-30$ \\
\hline PN108 & calcineurin temperature suppressor Cts1 [Cryptococcus neoformans] & 42.2 & 0.01 \\
\hline PN109 & triple gene block 1 [Cymbidium mosaic virus] & 322 & $5.00 \mathrm{E}-87$ \\
\hline PN110 & triple gene block 1 [Cymbidium mosaic virus] & 343 & $2.00 \mathrm{E}-93$ \\
\hline PN111 & hypothetical protein [Leptospira interrogans serovar lai str. 56601] & 31.6 & 3.6 \\
\hline PN112 & triple gene block 1 [Cymbidium mosaic virus] & 335 & $3.00 \mathrm{E}-92$ \\
\hline PN113 & triple gene block 1 [Cymbidium mosaic virus] & 337 & $1.00 \mathrm{E}-91$ \\
\hline PN114 & OSJNBa0091D06.22 [Oryza sativa (japonica cultivar-group)] & 102 & $1.00 \mathrm{E}-20$ \\
\hline PN115 & triple gene block 1 [Cymbidium mosaic virus & 338 & $4.00 \mathrm{E}-92$ \\
\hline PN116 & triple gene block 3 [Cymbidium mosaic virus] & 94.4 & $4.00 \mathrm{E}-19$ \\
\hline PN117 & RNA replicase [Cymbidium mosaic virus] & 92 & $2.00 \mathrm{E}-18$ \\
\hline PN118 & RNA dependent RNA polymerase [Cymbidium mosaic virus] & 405 & e-112 \\
\hline PN119 & triple gene block 2 [Cymbidium mosaic virus] & 112 & $2.00 \mathrm{E}-24$ \\
\hline PN120 & coat protein [Cymbidium mosaic virus] & 201 & $2.00 \mathrm{E}-51$ \\
\hline PN121 & RNA dependent RNA polymerase [Cymbidium mosaic virus] & 384 & e-105 \\
\hline PN122 & chaperonin 60 alpha subunit [Canavalia lineata] & 69.7 & $1.00 \mathrm{E}-11$ \\
\hline PN123 & triple gene block 1 [Cymbidium mosaic virus] & 419 & e-116 \\
\hline PN124 & putative zinc finger protein [Oryza sativa (japonica cultivar-group)] & 316 & $4.00 \mathrm{E}-86$ \\
\hline PN125 & triple gene block 3 [Cymbidium mosaic virus] & 91.3 & $3.00 \mathrm{E}-18$ \\
\hline PN126 & RNA dependent RNA polymerase [Cymbidium mosaic virus] & 284 & $1.00 \mathrm{E}-75$ \\
\hline PN127 & putative senescence-associated protein [Pisum sativum $]$ & 248 & $4.00 \mathrm{E}-72$ \\
\hline PN129 & RNA dependent RNA polymerase [Cymbidium mosaic virus] & 287 & $4.00 \mathrm{E}-77$ \\
\hline PN130 & RNA dependent RNA polymerase [Cymbidium mosaic virus] & 287 & $4.00 \mathrm{E}-77$ \\
\hline PN131 & RNA dependent RNA polymerase [Cymbidium mosaic virus] & 253 & e-107 \\
\hline PN132 & RNA dependent RNA polymerase [Cymbidium mosaic virus] & 317 & e-110 \\
\hline PN133 & putative coatomer complex subunit [Arabidopsis thaliana] & 286 & $2.00 \mathrm{E}-76$ \\
\hline PN134 & triple gene block 1 [Cymbidium mosaic virus] & 425 & e-118 \\
\hline PN135 & TPA: hypothetical class II basic helix-loop-helix protein [Homo sapiens] & 34.3 & 2.1 \\
\hline PN136 & triple gene block 1 [Cymbidium mosaic virus] & 342 & $3.00 \mathrm{E}-93$ \\
\hline PN137 & triple gene block 1 [Cymbidium mosaic virus] & 302 & $4.00 \mathrm{E}-91$ \\
\hline PN138 & MP1 [Cymbidium mosaic virus $]$ & 131 & $3.00 \mathrm{E}-30$ \\
\hline PN139 & elongation factor 1 alpha [Pyrus pyrifolia] & 144 & $5.00 \mathrm{E}-34$ \\
\hline PN140 & triple gene block 2 [Cymbidium mosaic virus] & 248 & $6.00 \mathrm{E}-65$ \\
\hline PN141 & RNA replicase [Cymbidium mosaic virus] & 158 & $3.00 \mathrm{E}-38$ \\
\hline PN142 & triple gene block 1 [Cymbidium mosaic virus] & 419 & e-116 \\
\hline PN143 & RNA dependent RNA polymerase [Cymbidium mosaic virus] & 443 & e-123 \\
\hline PN144 & endomembrane protein 70 , putative [Arabidopsis thaliana] & 302 & $5.00 \mathrm{E}-81$ \\
\hline PN145 & triple gene block 2 [Cymbidium mosaic virus] & 35.8 & 0.17 \\
\hline PN147 & coat protein [Cymbidium mosaic virus] & 109 & $8.00 \mathrm{E}-24$ \\
\hline PN148 & triple gene block 1 [Cymbidium mosaic virus] & 351 & e-102 \\
\hline PN149 & triple gene block 2 [Cymbidium mosaic virus] & 89.7 & $8.00 \mathrm{E}-18$ \\
\hline PN150 & S-adenosyl-L-methionine decarboxylase [Dendrobium crumenatum] & 138 & $3.00 \mathrm{E}-32$ \\
\hline PN151 & RNA replicase [Cymbidium mosaic virus] & 328 & $2.00 \mathrm{E}-88$ \\
\hline
\end{tabular}

${ }^{a}$ Sequence description of the highest scoring alignments described by one line summaries

${ }^{b}$ Scores (bits) assigned to an alignment calculated by summing the scores normalizing with the statistical variables for each position in the alignment.

${ }^{c}$ Expect (E) value describes the statistical significance threshold for reporting matches against database sequences. 
Tab. 7 Annotation of cDNA clones enriched in peloric flower buds from SSH flower-leaves analysis

\begin{tabular}{|c|c|c|c|}
\hline Clone ID & Description $^{\mathrm{a}}$ & Score (bits) ${ }^{\mathrm{b}}$ & E value $^{\mathrm{c}}$ \\
\hline D1 & Tubulin beta- 2 chain [Beta-2 tubulin] & 114 & $5.00 \mathrm{E}-25$ \\
\hline D3 & hypothetical protein XP_155099[Mus musculus] & 31.2 & 3.8 \\
\hline D4 & prunasin hydrolase isoform PHA precursor [Prunus serotina] & 218 & $7.00 \mathrm{E}-56$ \\
\hline D5 & water channel-like protein [Arabidopsis thaliana] & 139 & $1.00 \mathrm{E}-32$ \\
\hline D6 & similar to Spindlin-like protein 2 (SPIN-2) [Rattus norvegicus] & 36.2 & 0.35 \\
\hline D 7 & unknown protein $[$ Oryza sativa $]$ & 209 & $3.00 \mathrm{E}-53$ \\
\hline D 8 & unknown protein $[$ Oryza sativa $]$ & 209 & $3.00 \mathrm{E}-53$ \\
\hline D9 & early light-induced protein-like protein [Retama raetam] & 158 & $6.00 \mathrm{E}-38$ \\
\hline D10 & early light-induced protein-like protein [Retama raetam] & 158 & $6.00 \mathrm{E}-38$ \\
\hline D12 & alpha tubulin [Physcomitrella patens] & 233 & $1.00 \mathrm{E}-60$ \\
\hline D13 & putative RNase [Oryza sativa (japonica cultivar-group)] & 125 & $3.00 \mathrm{E}-28$ \\
\hline D14 & unknown protein $(\mathrm{sp} \mid \mathrm{P} 72777)$-related [Arabidopsis thaliana $]$ & 80.9 & $8.00 \mathrm{E}-15$ \\
\hline D15 & lipid transfer protein homolog [Triticum aestivum $]$ & 73.2 & $9.00 \mathrm{E}-13$ \\
\hline D16 & silverleaf whitefly-induced protein 3 [Cucurbita pepo] & 204 & $9.00 \mathrm{E}-52$ \\
\hline D18 & $\begin{array}{l}\text { protease inhibitor/seed storage/lipid transfer protein (LTP) family } \\
\text { [Arabidopsis thaliana] }\end{array}$ & 35 & 0.26 \\
\hline D19 & ribosomal protein RL5 [Cicer arietinum] & 102 & $1.00 \mathrm{E}-21$ \\
\hline D20 & $\begin{array}{l}\text { transcription factor PCF6 [Oryza sativa (japonica cultivar-group)]; TCP } \\
\text { family transcription factor }\end{array}$ & 49.7 & $4.00 \mathrm{E}-05$ \\
\hline $\mathrm{D} 21$ & hypothetical protein F8F16.250 - [Arabidopsis thaliana $]$ & 30.8 & 4.2 \\
\hline D22 & Ferrochelatase II, chloroplast precursor (Protoheme ferro-lyase) & 301 & $6.00 \mathrm{E}-81$ \\
\hline D24 & putative RNase $\mathrm{H}$ [Arabidopsis thaliana] & 115 & $1.00 \mathrm{E}-25$ \\
\hline D26 & hypothetical protein [Encephalitozoon cuniculi] & 32 & 3.7 \\
\hline $\mathrm{D} 27$ & unknown $[$ Zea mays] & 87.8 & $3.00 \mathrm{E}-17$ \\
\hline D28 & hypothetical protein [swollen duckweed] & 69.3 & $1.00 \mathrm{E}-11$ \\
\hline D29 & cellulose synthase-7 [Zea mays] & 310 & $9.00 \mathrm{E}-84$ \\
\hline D31 & pectinesterase family [Arabidopsis thaliana] & 135 & $1.00 \mathrm{E}-31$ \\
\hline D32 & hypothetical protein [Bacteroides thetaiotaomicron VPI-5482] & 31.2 & 3.8 \\
\hline D35 & polyamine oxidase [Hordeum vulgare subsp. vulgare] & 224 & $1.00 \mathrm{E}-57$ \\
\hline D38 & plastid-lipid associated protein PAP/fibrillin family [Arabidopsis thaliana] & 147 & $1.00 \mathrm{E}-57$ \\
\hline D39 & CG8146-PA [Drosophila melanogaster] & 31.6 & 3.2 \\
\hline D42 & expressed protein [Arabidopsis thaliana] & 137 & $9.00 \mathrm{E}-32$ \\
\hline D43 & GLP_78_3038_1476 [Giardia lamblia ATCC 50803] & 32 & 2.4 \\
\hline D44 & plasma membrane aquaporin [Vitis vinifera] & 209 & $8.00 \mathrm{E}-54$ \\
\hline D45 & late embryogenesis abundant protein $-[$ Arabidopsis thaliana $]$ & 74 & $4.00 \mathrm{E}-13$ \\
\hline D46 & AtHVA22a $[$ Arabidopsis thaliana $]$ & 55.5 & $2.00 \mathrm{E}-07$ \\
\hline D47 & unknown protein $[$ Arabidopsis thaliana $]$ & 146 & $3.00 \mathrm{E}-34$ \\
\hline D48 & GDSL-motif lipase/hydrolase protein [Arabidopsis thaliana] & 177 & $1.00 \mathrm{E}-43$ \\
\hline D49 & histone $\mathrm{H} 2 \mathrm{~A}[$ Euphorbia esula $]$ & 167 & $5.00 \mathrm{E}-41$ \\
\hline D50 & GDSL-motif lipase/hydrolase protein [Arabidopsis thaliana] & 168 & $5.00 \mathrm{E}-41$ \\
\hline D52 & AtHVA22a $[$ Arabidopsis thaliana $]$ & 55 & $2.00 \mathrm{E}-07$ \\
\hline D54 & beta-tubulin [Cicer arietinum $]$ & 55 & $2.00 \mathrm{E}-07$ \\
\hline D55 & unknown protein $[$ Oryza sativa $]$ & 194 & $1.00 \mathrm{E}-48$ \\
\hline D56 & phospholipid transfer protein [Aerides japonica] & 166 & $7.00 \mathrm{E}-41$ \\
\hline D57 & arginine decarboxylase 2 [Nicotiana tabacum] & 172 & $7.00 \mathrm{E}-43$ \\
\hline D58 & unknown protein $[$ Oryza sativa] & 142 & $7.00 \mathrm{E}-43$ \\
\hline D60 & GDSL-motif lipase/hydrolase protein [Arabidopsis thaliana] & 177 & $8.00 \mathrm{E}-44$ \\
\hline D61 & putative carboxymethylenebutenolidase [Oryza sativa] & 139 & $6.00 \mathrm{E}-33$ \\
\hline D63 & GDSL-motif lipase/hydrolase protein [Arabidopsis thaliana] & 176 & $2.00 \mathrm{E}-43$ \\
\hline D64 & GDSL-motif lipase/hydrolase protein [Arabidopsis thaliana] & 114 & $3.00 \mathrm{E}-25$ \\
\hline D65 & conserved hypothetical protein [Borrelia burgdorferi B31] & 32 & 2.6 \\
\hline D66 & proline-rich-like protein [Asparagus officinalis] & 51.2 & $3.00 \mathrm{E}-06$ \\
\hline D70 & tocopherol cyclase [Eucalyptus gunnii] & 163 & $5.00 \mathrm{E}-40$ \\
\hline D71 & acyltransferase homolog $[$ Petunia $x$ hybrida $]$ & 134 & $8.00 \mathrm{E}-31$ \\
\hline
\end{tabular}


Tab. 7 Annotation of cDNA clones enriched in peloric flower buds from SSH flower-leaves analysis (continued-1)

\begin{tabular}{clcc}
\hline Clone ID & \multicolumn{1}{c}{ Description $^{\mathrm{a}}$} & Score $^{(\text {bits })^{\mathrm{b}}}$ & $\mathrm{E} \mathrm{value}^{\mathrm{c}}$ \\
\hline D78 & P0485B12.26 [Oryza sativa (japonica cultivar-group)] & 75.1 & $4.00 \mathrm{E}-13$ \\
D79 & protein kinase family [Arabidopsis thaliana] & 153 & $2.00 \mathrm{E}-36$ \\
D80 & putative 60S ribosomal protein L44 [Oryza sativa] & 201 & $2.00 \mathrm{E}-51$ \\
D81 & chloroplast ribosomal protein S22 [Spinacia oleracea] & 115 & $2.00 \mathrm{E}-25$ \\
D82 & lipid transfer protein precursor [Davidia involucrata] & 68.6 & $2.00 \mathrm{E}-11$ \\
D83 & putative ribosomal protein L19 [Oryza sativa] & 129 & $2.00 \mathrm{E}-29$ \\
D84 & P0705A05.30 [Oryza sativa] & 213 & $2.00 \mathrm{E}-62$ \\
D85 & P0498E12.14 [Oryza sativa] & 68.2 & $6.00 \mathrm{E}-11$ \\
D86 & senescence-associated protein family [Arabidopsis thaliana] & 96.7 & $2.00 \mathrm{E}-19$ \\
D89 & lipid transfer protein precursor [Davidia involucrata] & 105 & $1.00 \mathrm{E}-22$ \\
D90 & phospholipid transfer protein [Aerides japonica] & 202 & $1.00 \mathrm{E}-51$ \\
D91 & lipid transfer protein precursor [Davidia involucrata] & 105 & $1.00 \mathrm{E}-22$ \\
\hline
\end{tabular}

${ }^{\text {a }}$ Sequence description of the highest scoring alignments described by one line summaries

${ }^{\text {b }}$ Scores (bits) assigned to an alignment calculated by summing the scores normalizing with the statistical variables for each position in the alignment.

${ }^{c}$ Expect (E) value describes the statistical significance threshold for reporting matches against database sequences.

terference remains to be elucidated. Elimination of false positive clones during SSH has been reported by using a Mirror Orientation Selection [42].

\section{Expression levels of selected ESTs in wild type and mutant flowers}

In order to confirm the differential expression of the cloned ESTs from both cDNA-RAPD and SSH, real-time RT-PCR using SYBR Green as fluorescence source was conducted to analyze selected clones to check their relative expression level in either wild type or peloric or semipeloric flower buds by comparing to the housekeeping gene. These clones were selected due to their probable role in cell division, hormone induction, and flower development. First, standard curves of the housekeeping gene, actin, and then selected target genes were generated with the ABI Prism 7900 detection system. Coefficients of determination $\left(R^{2}\right)$ for the standard curves were more than 0 . 96 for most ESTs examined, except for the clones ZOPB10M-60-2(1) and LOPW06N-11-3(19), but all above 0.82-0.91 (Fig. 4).

Expression level of the selected clones was shown in Fig. 5, except of one WD-40 repeat clone OPT05M-50 (Tab. 3) which did not show significant difference between wild type and mutants (data not shown). The clone LOPW02N-3-2(3), encoding a TGA1a-like protein belonged to the bZIP family, was 3-fold and 1.4-fold upregulated in the wild type as compared to the peloric mutant and semi-peloric mutant respectively (Fig. 5A). The clone LOPW06N-11-3(19) was slightly up-regulated in the peloric and semi-peloric mutants than the wild type (Fig. 5B). The Clone LOPW07N-13(29) was down-regulated in the semi-peloric flower buds as compared to the wild type and the peloric (Fig. 5D). Two clones, ZOPAA01M2(72) and 607FD12, were highly up-regulated in the prloric mutants. The ZOPAA01M-2(72) clone is a CyMV RNAdependent RNA polymerase, which was expressed only at basal level in the wild type and semi-peloric flower buds, but highly in the peloric mutants (Fig. 5C). The other highly expressed clone 607FD12 is a retroelement, which was also 6-fold expressed in the peloric mutant than the wild type (Fig. 5E). An unknown protein clone LOPW02M-41(7) was down-regulated in the semi-peloric flower buds, and about 1.6-fold expressed in the peloric flower buds and 1.3-fold in the wild type (Fig. 5F). ZOPB10M-60-2 (1) obtained from cDNA-RAPD represents an auxin-regulated dual specificity cytosolic kinase. It was highly expressed in the peloric mutants, with 3-fold higher than the wild type and about 1.8 fold-in semi-peloric mutants (Fig. 5G). A serine/threonine protein kinase gene $A P K 2 a$ was reported to be negatively regulated by the AGAMOUS protein in flower development [43]. The Arabidopsis receptor-like kinase ERECTA also plays a role in inflorescence architecture [44]. Finally, clone ZOPAA12M-24(65) from cDNA-RAPD, encoding a cyclophilin-like protein, was slightly up-regulated in the peloric mutants (Fig. 5H). One clone isolated from SSH experiment with 1.6-fold increase in transcripts in the peloric mutants has sequence similarity to a transcriptional factor PCF6 and a TCP family member (Fig. 5I).

\section{DISCUSSION}

SSH has been reported as a tool to compare differentially expressed genes during development and in responses to stresses, pests and somaclonal variations $[31,45]$. Since many cultivated orchids tended to be infected by different 

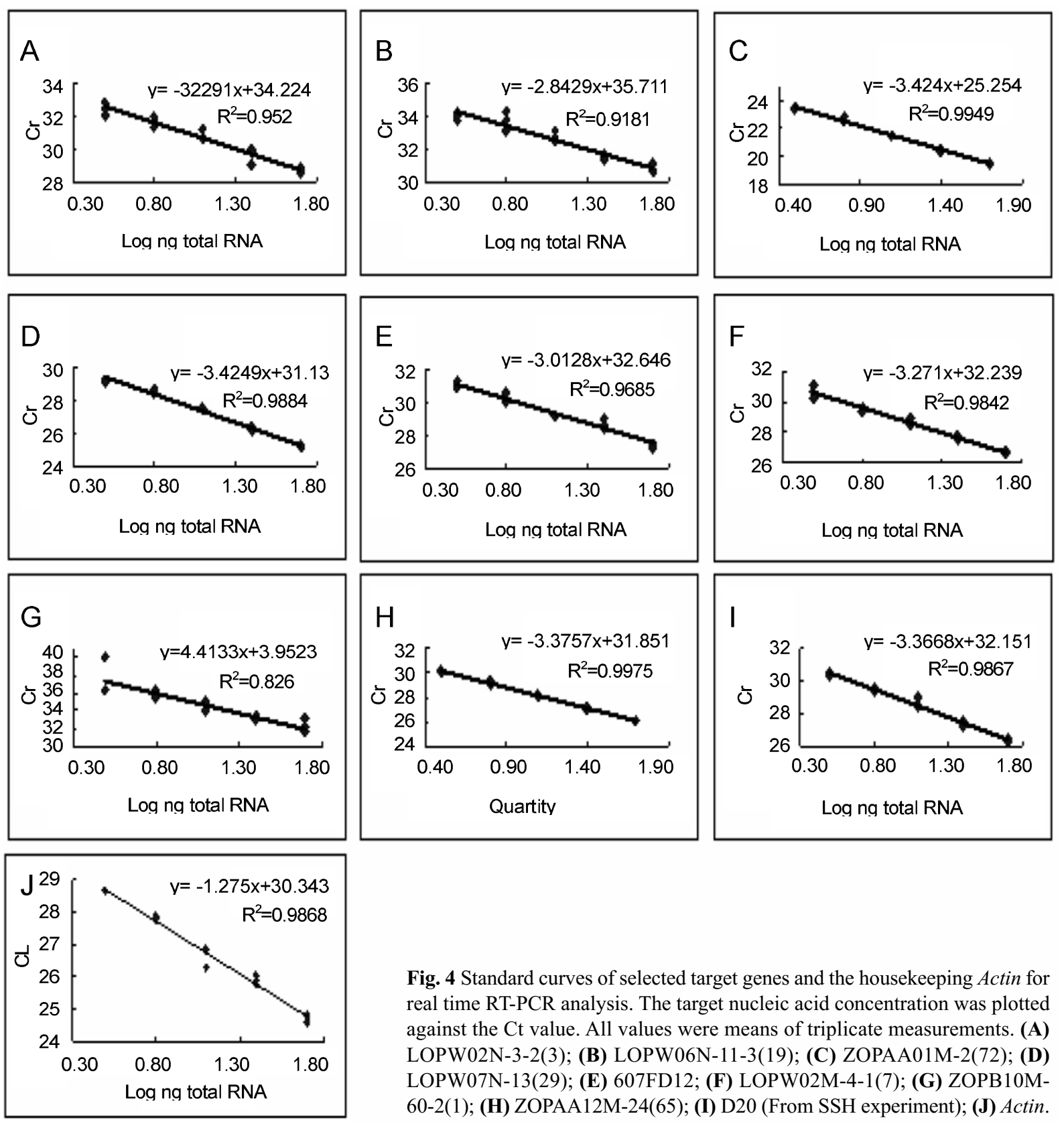

Fig. 4 Standard curves of selected target genes and the housekeeping Actin for real time RT-PCR analysis. The target nucleic acid concentration was plotted against the $\mathrm{Ct}$ value. All values were means of triplicate measurements. (A) LOPW02N-3-2(3); (B) LOPW06N-11-3(19); (C) ZOPAA01M-2(72); (D) LOPW07N-13(29); (E) 607FD12; (F) LOPW02M-4-1(7); (G) ZOPB10M60-2(1); (H) ZOPAA12M-24(65); (I) D20 (From SSH experiment); (J) Actin.

viruses, such as the CyMV and ORSV [46]), the abundant virus transcripts in the plant cells and tissues might interfere with the SSH or the cDNA-AFLP analysis [47]. In this study, although limited numbers of differentially expressed ESTs were obtained, several interesting clones derived from both suppression subtractive hybridization and cDNA-RAPD analyses revealed potential roles in flower development. A big portion of the subtracted clones belonged to the orchid virus, although it is not clear if the virus infection may cause the phenotypic change. There are clones differentially expressed in the mutant flower buds and one of the most interesting ones is D20, which encodes a potential TCP domain protein. The study on bilateral symmetry in snapdragon flower showed that the radial symmetry was caused by mutations in cycloidea and dichotoma genes [48, 49]. Both gene products belong to the members of the TCP family proteins that control plant development from different aspects [39-41]. We have attempted to clone the cycloidea (cyc) homolog in Phalaenopsis orchids by using degenerate primers based on conserved amino acid sequence of $c y c$ homologs, but failed (data not shown). The cloning of TCP homolog, D20 from peloric flower buds by SSH analysis (Tab. 7) enables us to further characterize the biological function 

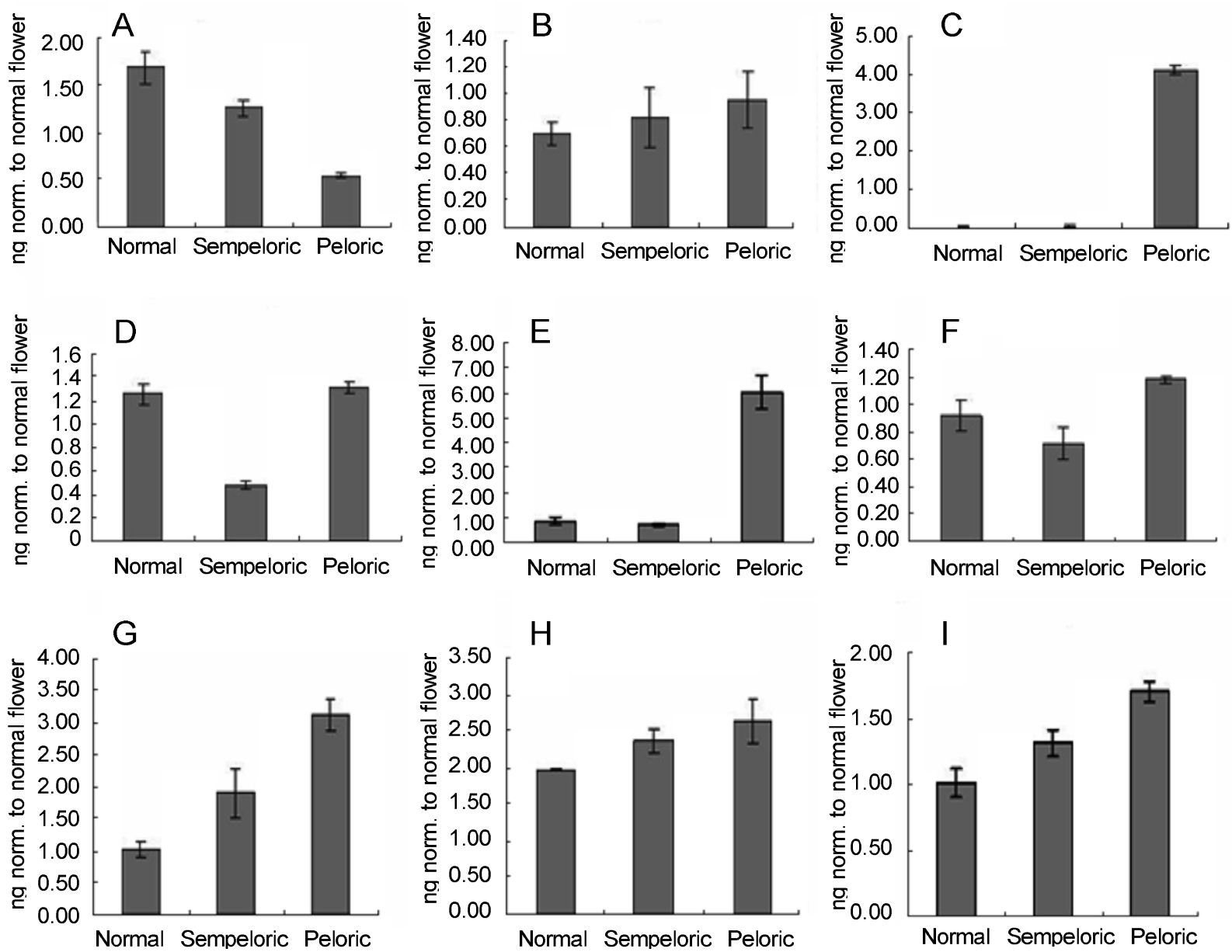

Fig. 5 Real-time RT-PCR analysis for expression levels of selected target genes of normal (wild type) and mutant flower buds of Phalaenopsis orchids from both cDNA-RAPD and suppression subtractive hybridization. (A) LOPW02N-3-2(3), encoding a TGA1alike protein; (B) LOPW06N-11-3(19), encoding a protein kinase; (C) ZOPAA01M-2(72), encoding CyMV RNA-dependent RNA polymerase; (D) LOPW07N-13(29), encoding a praline iminopeptidase; (E) 607FD12, a retroelement; (F) LOPW02M-4-1(7), encoding an unknown protein; (G) ZOPB10M-6-2(1), encoding auxin-regulated dual specificity cytosolic kinase; (H) ZOPAA12M24(65), encoding cyclophilin-like protein; (I) D20, encoding a transcriptional factor PCF6 or TCP family protein.

of D20 in floral symmetry in Phalaenopsis orchids.

Bulge of the central part of lateral petals in the peloric flowers might be epidermal cell origin. The interaction between transcription factor such as the homeobox genes and TCP homolog and some other protein factors may lead to ectopic cell division in the petals to form the bulge structure $[45,50]$. One homoebox gene was recently cloned from the phalaenopsis inflorescence by using degenerate primers based on multiple nucleotide sequence alignment. The homeobox shows homology to the ovulespecific homeobox gene [51] and a rice GL2-type homeobox gene Rocl specifically expressed in the protoderm or epidermal layer of rice embryo [52]. Stimuli of hormones, such as the auxin-regulated dual specificity cytosolic kinase may induce unusual cell division in the bulge regions of the peloric petals as shown in Fig. 5G. The unequal distribution of auxin may lead to unusual cell division in certain part of a leaf tissue [53], which may imply similar situation in phalaenopsis flowers. The leaf of the asymmetric leaves 1 mutant of Arabidopsis was reverted by applying auxin onto the leaves, an indication of the role of polar auxin transport in leaf patterning [53]. The putative auxin-regulated gene also shares high homology to serine/ threonine/tyrosine-specific protein kinases, suggesting a role in the signal transduction pathway during cell division or plant development [54-56].

In conclusion, we have obtained hundreds of ESTs from the wild type and peloric mutant flower buds of the Phalaenopsis hybrids by using techniques of cDNA-RAPD and SSH. Biased as well as redundant clones towards the wild type or the peloric mutants revealed potential differential transcription regulation. Several analysed ESTs, such 
as the retroelement, TCP family proteins, auxin-regulated kinase may play a role in the orchid flower development. One question we can ask is whether these up-regulated ESTs due to the epigenetic regulation mechanism, such as DNA hypomethylation? DNA methylation has been implied as a mechanism regulating plant development such as vernalization and somaclonal variation [18, 23, 24, 57-60]. Recently, we have cloned the full length cDNA of a DNA cytosine methyltransferase and a receptor-related protein kinase, ERECTA-like gene from the SSH study (Tab. 5). Their function in orchid flower development will be further characterized through complementation of Arabidopsis mutants and via knockout orchids by genetic approach.

\section{ACKNOWLEDGEMENTS}

We are grateful to Sogo Orchids and Taida Orchids for providing plant materials. This work was supported by grants from the Council of Agriculture (Grant no. 91AS3.1.3-FD-Z1-4 and 92AS-4.2.3-FD-Z1-7), Taiwan.

\section{Received, June 10, 2005}

Revised, Aug 5, 2005

Accepted, Aug 16, 2005

\section{REFERENCES}

1 Griesbach RJ. Development of Phalaenopsis orchids for the mass-market. 458-65. In: Janick J, Whipkey A (eds.), Trends in New Crops and New Uses. 2002; ASHS Press, Alexandria, VA.

2 Hsu CC. Protocorm-like body induction and plant regeneration from etiolated leaves of in vitro Phalaenopsis. Master thesis, Institute of Tropical Agr And Intl Cooperation, Natl Pingtung Univ of Sci \& Technol 2003; 88.

3 Hsu CC, Chen FC. Plant regeneration from protocorm-like bodies induced in etiolated leaves of Phalaenopsis aphrodite Rchb. f. J Chinese Soc Hort Sci 2003; 49:335-42.

4 Tanaka M. Micropropagation of Phalaenopsis spp. In: Bajaj YPS, (ed) Biotechnology in agriculture and forestry 1992; 20: 246-68.

5 Tokuhara K, Mii M. Micropropagation of Phalaenopsis and Doritaenopsis by culturing shoot tips of flower stalk buds. Plant Cell Rep 1993; 13:7-11.

6 Chen FC, Chen TC. Effect of salt strength and organic additives on the in vitro growth of protocorm-like-bodies and plantlets of Oncidium Gower Ramsey. J Chinese Soc Hort Sci 1998; 44:40312.

7 Chen YC, Chang C, Chang WC. A reliable protocol for plant regeneration from callus cultures of Phalaenopsis. In Vitro Cell Dev Biol Plant 2000; 36:420-3.

8 Ishii Y, Takamura T, Goi M, Tanaka M. Callus induction and somatic embryogenesis of Phalaenopsis. Plant Cell Rep 1998; 17:446-50.

9 Tokuhara K, Mii M. Somaclonal variations in flower and inflorescence in micropropagated plants through flower stalk bud of Phalaenopsis and Doritaenopsis axis culture. Plant Biotech 1998; 15:23-8.
10 Mishiba K, Mii M. Increasing ploidy level in cell suspension cultures of Doritaenopsis by exogenous application of 2,4-dichlorophenoxyacetic acid. Physiol. Plant. 2001; 112:142-8.

11 Chen YH, Chen FC. Analysis of expressed transcripts from Phalaenopsis mutant flower buds. In: $8^{\text {th }}$ Proc. Asia Pacific Orchid Conference, 2004; Tainan, Taiwan.

12 Chen FC, Chen YH, Lee WL, Chiang SF, Tsai YJ. Orchid mutants from tissue culture-Implication of gene expression to orchid development. In: $8^{\text {th }}$ Proc. Asia Pacific Orchid Conference, 2004; Tainan, Taiwan.

13 Hirochika H. Activation of tobacco retrotransposons during tissue culture. EMBO J 1993; 12:2521-8.

14 Hirochika H, Sugimoto K, Otsuki Y, Tsugawa H, Kanda M. Retrotransposons of rice involved in mutations induced by tissue culture. Proc. Natl Acad Sci U S A 1996; 93:7783-8.

15 Kaeppler SM, Phillips RL. Tissue culture-induced DNA methylation variation in maize. Proc Natl Acad Sci U S A 1993; 90: 8773-6.

16 Kaeppler SM, Kaeppler HF, Rhee Y. Epigenetic aspects of somaclonal variation in plants. Plant Mol Biol 2000; 43:179-88.

17 Kimura Y, Tosa Y, Shimada S, et al. OARE-1, a Ty1-copia retrotransposon in oat activated by abiotic and biotic stresses. Plant Cell Physiol 2001; 42:1345-54.

18 Kubis SE, AM Castilho, AV Vershinin, Heslop-Harrison JS. Retroelements, transposons and methylation status in the genome of oil palm (Elaeis guineensis) and the relationship to somaclonal variation. Plant Mol Biol 2003; 52:69-79.

19 Price Z, Dumortier F, MacDonald W, Mayes S. Characterisation of copia-like retrotransposons in oil palm (Elaeis guineensis Jacq.). Theor Appl Genet 2002; 104:860-7.

20 Grandbastien MA. Activation of plant retrotransposons under stress conditions. Trends Plant Sci 1998; 3:181-7.

21 Chen WH, Chen TM, Fu YM, Hsieh RM, Chen WS. Studies on somaclonal variation in phalaenopsis. Plant Cell Rep 1998; 18: 7-13.

22 Rival A, Bertrand L, Beulé T, et al. Suitability of RAPD analysis for the detection of somaclonal variants in oil palm. Plant Breed 1998; 117:73-6.

23 Jaligot E, Beule T, Rival A. Methylation- sensitive RFLPs: characterisation of two oil palm markers showing somaclonal variation-associated polymorphism. Theor Appl Genet 2002; 104:1263-9.

24 Jaligot E, Rival A, Beule T, Dussert S, Verdeil J-L. Somaclonal variation in oil palm (Elaeis guineensis Jacq.): the DNA methylation hypothesis. Plant Cell Rep 2000; 7:684-90.

25 Alou AH, Azaiez A, Jean M, Belzile FJ. Involvement of the Arabidopsis thaliana AtPMS1 gene in somatic repeat instability. Plant Mol Biol 2004; 56:339-49.

26 Leonard JM, Bollmann SR, Hays JB. Reduction of stability of arabidopsis genomic and transgenic DNA-repeat sequences (microsatellites) by inactivation of AtMSH2 mismatch-repair function. Plant Physiol 2003; 133:328-38.

27 Schmidt AL, Mitter V. Microsatellite mutation directed by an external stimulus. Mutat Res 2004; 568:233-43.

28 Jones WE, Kuehnle AR, Arumuganathan K. Nuclear DNA content of 26 orchid (Orchidaceae) genera with emphasis on Dendrobium. Ann Bot 1998; 82:189-94.

29 Kao Y-Y, Chang S-B, Lin T-Y, et al. Differential accumulation of heterochromatin as a cause for karyotype variation in 
Phalaenopsis orchids. Ann Bot 2001; 87:387-395.

30 Lin S, Lee H-C, Chen W-H, et al. Nuclear DNA contents of Phalaenopsis sp. and Doritis pulcherrima. J Amer Soc Hort Sci 2001; 126:195-9.

31 Diatchenko L, Lau YF, Campbell AP, et al. Suppression subtractive hybridization: a method for generating differentially regulated or tissue-specific cDNA probes and libraries. Proc Natl Acad Sci U S A 1996; 93:6025-30.

32 Altschul SF, Madden TL, Schaffer AA, et al. Gapped BLAST and PSI-BLAST: a new generation of protein database search programs. Nucleic Acids Res 1997; 25:3389-402.

33 Bohnert HJ, P. Ayoubi C, Borchert RA, et al. A genomics approach towards salt stress tolerance. Plant Physiol Biochem 2001; 39:295-311.

34 Czechowski T, Bari RP, Stitt M, Scheible WR, Udvardi MK. Real-time RT-PCR profiling of over 1400 Arabidopsis transcription factors: unprecedented sensitivity reveals novel root- and shoot-specific genes. Plant J 2004; 38:366-79.

35 Gamas P, Niebel Fde C, Lescure N, Cullimore J. Use of a subtractive hybridization approach to identify new Medicago truncatula genes induced during root nodule development. Mol Plant Microbe Interact 1996; 9:233-42.

36 Ge YX, Angenent GC, Wittich PE, et al. NEC1, a novel gene, highly expressed in nectary tissue of Petunia hybrida. Plant $\mathbf{J}$ 2000; 24:725-34.

37 Becerra C, Jahrmann T, Puigdomenech P, Vicient CM. Ankyrin repeat-containing proteins in Arabidopsis: characterization of a novel and abundant group of genes coding ankyrin-transmembrane proteins. Gene 2004; 340:111-21.

38 Silhavy D, Molnár A, Lucioli A, et al. A viral protein suppresses RNA silencing and binds silencing-generated, 21- to 25-nucleotide double-stranded RNAs. EMBO J 2002; 21:3070-80.

39 Cubas P, Vincent C, Coen E. An epigenetic mutation responsible for natural variation in floral symmetry. Nature $1999 ; 401: 157-$ 61.

40 Cubas P, Lauter N, Doebley J, Coen E. The TCP domain: a motif found in proteins regulating plant growth and development. Plant J 1999; 18:215-22.

41 Kosugi S, Ohashi Y. DNA binding and dimerization specificity and potential targets for the TCP protein family. Plant J 2002; 30:337-48.

42 Rebrikov DV, Britanova OV, Gurskaya NG, et al. Mirror orientation selection (MOS): a method for eliminating false positive clones from libraries generated by suppression subtractive hybridization. Nucleic Acids Res 2000; 28, E90.

43 Ito T, Takahashi N, Shimura Y, Okada K. A serine/threonine protein kinase gene isolated by an in vivo binding procedure using the Arabidopsis floral homeotic gene product, AGAMOUS. Plant Cell Physiol 1997; 38:248-58.

44 Shpak ED, Berthiaume CT, Hill EJ, Torii KU. Synergistic interaction of three ERECTA-family receptor-like kinases controls Arabidopsis organ growth and flower development by promoting cell proliferation. Development 2004; 131:1491-501.
45 Venglat SP, Dumonceaux T, Rozwadowski K, et al. The homeobox gene BREVIPEDICELLUS is a key regulator of inflorescence architecture in Arabidopsis. Proc Natl Acad Sci U S A 2002; 99: 4730-35.

46 Seoh ML, Wong SM, Zhang L. Simultaneous TD/RT-PCR detection of cymbidium mosaic potexvirus and odontoglossum ringspot tobamovirus with a single pair of primers. J Virol Methods 1998; 72:197-204.

47 Chen HH, Tsai WC, Lin S, Chen WH. cDNA-AFLP analysis of differential gene expression in the flower buds of Phalaenopsis HSIANG FEI cv. H. F. and its somaclonal variant. Plant \& Animal Genome IX 2001; P323

48 Hileman LC, Kramer EM, Baum DA. Differential regulation of symmetry genes and the evolution of floral morphologies. Proc Natl Acad Sci U S A 2003; 100:12814-9.

49 Luo D, Carpenter R, Copsey L, et al. Control of organ asymmetry in flowers of Antirrhinum. Cell 1999; 99:367-76.

50 Kappen C. Analysis of a complete homeobox gene repertoire: Implications for the evolution of diversity. Proc Natl Acad Sci U S A 2000; 97:4481-86.

51 Nadeau JA, Zhang XS, Li J, O’Neill SD. Ovule development: identification of stage-specific and tissue-specific cDNAs. Plant Cell 1996; 8:213-39.

52 Ito M, Sentoku N, Nishimura A, et al. Position dependent expression of GL2-type homeobox gene, Rocl: significance for protoderm differentiation and radial pattern formation in early rice embryogenesis. Plant J 2002; 29:497-507.

53 Zgurski JM, Sharma R, Bolokoski DA, Schultz EA. Asymmetric auxin response precedes asymmetric growth and differentiation of asymmetric leafl and asymmetric leaf 2 arabidopsis leaves. Plant Cell 2005; 17:77-91.

54 Hirayama T, Oka A. Novel protein kinase of Arabidopsis thaliana (APK1) that phosphorylates tyrosine, serine and threonine. Plant Mol Biol 1992; 20:653-62.

55 Hwang I, Goodman HM. An Arabidopsis thaliana root-specific kinase homolog is induced by dehydration, $\mathrm{ABA}$, and $\mathrm{NaCl}$. Plant J 1995; 8:37-43.

56 Moran TV, Walker JC. Molecular cloning of two novel protein kinase genes from Arabidopsis thaliana. Biochim Biophys Acta 1993; 1216:9-14.

57 Burn JE, Bagnall DJ, Metzger JD, Dennis ES, Peacock WJ. DNA methylation, vernalization, and the initiation of flowering. Proc Natl Acad Sci U S A 1993; 90:287-91.

58 Finnegan EJ, Genger RK, Kovac K, Peacock WJ, Dennis ES. DNA methylation and the promotion of flowering by vernalization. Proc Natl Acad Sci U S A 1998; 95:5824-9.

59 Jaligot E, Beule T, Baurens FC, Billotte N, Rival A. Search for methylation-sensitive amplification polymorphisms associated with the mantled variant phenotype in oil palm (Elaeis guineensis Jacq). Genome 2004; 47:224-8.

60 Sheldon CC, Burn JE, Perez PP, et al. The FLF MADS box gene: a repressor of flowering in Arabidopsis regulated by vernalization and methylation. Plant Cell 1999; 11:445-58. 